HID 48 (2021)

\title{
LAS ÓRDENES MILITARES EN LOS CONFLICTOS ENTRE CASTILLA Y PORTUGAL Y SU EVOLUCIÓN EN EL SIGLO XV ${ }^{1}$
}

\author{
MILITARY ORDERS IN THE CONFLICTS BETWEEN CASTILE AND \\ PORTUGAL AND THEIR EVOLUTION IN THE $15^{\mathrm{TH}}$ CENTURY
}

\author{
JUAN BoIX SALVADOR \\ Universidad Autónoma de Madrid \\ delboj6@gmail.com ORCID: https://orcid.org/0000-0002-0646-7213
}

RESUMEN: Este trabajo trata de mostrar el papel de las órdenes militares de Castilla y de Portugal, en los conflictos que enfrentaron a las dos monarquías durante el siglo XV, en particular en las guerras de frontera. Para ello se abordará la intervención de los reyes en las órdenes a las que sometieron a su poder y que se tradujo en el apoyo de las mismas a sus políticas, aunque no siempre fue así. En la guerra civil castellana hubo disidencias en el interior de las órdenes, según respalden o no al monarca, como también ocurrió en la guerra de sucesión castellana de 1475-1479. Las órdenes nacionales portuguesas fueron gobernadas por la familia real y apoyaron a su soberano.

PALABRAS ClaVE: Órdenes militares; Castilla y Portugal siglo XV; intervencionismo de las monarquías; guerra de fronteras; guerra civil castellana; guerra de sucesión castellana.

ABSTRACT: This work tries to show the role of the military orders of Castile and Portugal, in the conflicts that confronted the two monarchies during the fifteenth century, in particular in the border wars. For this, the intervention of the kings in the orders to which they submitted to their power will be addressed and that resulted in their support for their policies, although this was not always the case. In the Castilian civil war there were dissidents within the orders, depending on whether or not they support the monarch, as also happened in the war of Castilian succession of 1475-1479. The Portuguese national orders were ruled by the royal family and supported their sovereign.

Recibido: 12-1-2021; Aceptado: 4-3-2021; Versión definitiva: 12-4-2021

1. Abreviaturas utilizadas: $\mathrm{AGS}=$ Archivo General de Simancas; $\mathrm{RAH}=$ Real Academia de la Historia; HID = Historia. Instituciones. Documentos.

Copyright: (C) Editorial Universidad de Sevilla. Este es un artículo de acceso abierto distribuido bajo los términos de la licencia de uso y distribución Creative Commons Reconocimiento-NoComercialSinObraDerivada 4.0 (CC BY-NC-ND 4.0) 
KEYWORDS: Military orders; Castile and Portugal $15^{\text {th }}$ century; interventionism of monarchies; border warfare; Castilian civil war; war of Castilian succession.

\section{INTRODUCCIÓN}

Las órdenes militares de los dos reinos se enfrentaron, sobre todo, en los espacios de la frontera entre ambos, en los conflictos en los que las monarquías de Castilla y Portugal quisieron dirimir sus diferencias e imponer su primacía en el siglo XV, continuación de los acaecidos en el siglo anterior. Habían perdido de vista su objetivo fundacional: la lucha contra los infieles, los musulmanes, consecuencia de lo que el profesor Ayala llama, para las órdenes castellanas, secularización de las mismas, es decir su acercamiento a los intereses de la nobleza y de la sociedad laica ${ }^{2}$. En Portugal, en el siglo XV se puede hablar de crise de vivência religiosa, con lo que representa en términos de laicisação de las órdenes, de su "aristocratización”, pues más de la mitad de los comendadores era de origen noble 3 .

A finales del siglo XIV e inicios del XV, se siguió con la guerra de fronteras, incursiones y la firma de treguas y paces entre los dos reinos hasta las paces definitivas de 1432, en un clima de entendimiento creciente, a partir de la década de los años veinte 4 . Más tarde, la aparición de dos bandos en la guerra civil castellana y la muerte de Enrique IV (1454-1474) propiciarán los enfrentamientos que llevaron a la guerra de sucesión castellana, aunque no impedirán la continuación de la guerra de desgaste hasta 1479-1480. A finales del siglo XV, la frontera hispano-portuguesa conocerá cierta tranquilidad y paz al cambiar los objetivos, con nuevas orientaciones hacia espacios exteriores a un lado y otro del Atlántico, a donde se dirigieron los intereses de las monarquías y de las noblezas.

Vamos a observar cómo evolucionan las órdenes militares en este siglo, por la injerencia de la realeza en el nombramiento de sus maestres y demás dignidades, así como por el interés de la nobleza en acaparar esos cargos y en inclinar las actividades de las mismas en uno u otro de los bandos que sembrarán de contiendas el reino de Castilla. Estudiaremos el papel de las órdenes en los conflictos entre Castilla y Portugal, en la guerra civil castellana y en la crisis sucesoria en este reino, con la intervención del monarca portugués.

Los historiadores siempre se han interesado por las órdenes militares, sobre todo por sus orígenes, reglas y desarrollo, aunque, según Carlos de Ayala, el gran cambio en la moderna historiografía de órdenes militares se produjo en España en la década de 1990, con la publicación de dos artículos que recogían el acaecer de las órdenes en la península ibérica. Desde entonces numerosos trabajos han visto la luz sobre las órdenes, en todos sus aspectos ${ }^{5}$. Los Encontros de Palmela

2. Ayala, 2019a, p. 64.

3. Fonseca, 2004, p. 328; 2013, p. 13.

4. Olivera, 2018, p. 59.

5. Ayala et al, 1992 y 1993; Izquierdo, Ruiz, 2000; Ayala, 2006 y 2019b; Montaña, 2009a; García Fitz, Novoa, 2018; Palacios S, 2018a y 2018 b. 
sobre Órdenes Militares han puesto de manifiesto un estado de la cuestión de esas investigaciones en España y Portugal, a los que podemos añadir algunos ejemplos de diversas publicaciones portuguesas e incorporar el trabajo de Paula Pinto Costa sobre el panorama historiográfico de las órdenes y el dirigido por J. Mattoso sobre la historiografía medieval de Portugal, con un capítulo sobre las órdenes militares portuguesas, sin olvidar el Repertório Bibliográfico da Historiografia Portuguesa, citado por Paula Costa ${ }^{6}$.

\section{CONFLICTOS INTERNOS E INTERVENCIONISMO EN LAS ÓRDENES MILITARES}

Las monarquías castellana y portuguesa quisieron controlar y dominar las órdenes militares de sus reinos, desde su creación y posterior evolución. Nombraban a sus dignatarios o influían en su elección o, al contrario, los desposeían de sus cargos. También se interesarían por ellas la nobleza. Éxitos y fracasos se sucederán en los propósitos de ambos estamentos, también atraídos, qué duda cabe, por la parte económica -rentas- de las órdenes.

Varios de los maestres eran de la realeza o próximos a los sectores dominantes de la sociedad con un proceder similar al resto de la nobleza laica ${ }^{7}$. Así, por ejemplo, el control de la orden de Calatrava pasará a manos de varios linajes nobles, Guzmán, Padilla, Carrillo o Girón ${ }^{8}$. La orden de Santiago tendrá como maestres a infantes, como Enrique de Aragón en 1409 o Alfonso de Castilla en 1462 o a figuras relevantes como Álvaro de Luna, Beltrán de la Cueva o Juan Pacheco, marqués de Villena; incluso Juan II (1453-1454) y Enrique IV (1454-1462) serán sus administradores. En la orden de Alcántara ocurrirá lo mismo, con los maestres Juan y Gutierre de Sotomayor y Juan de Stúñiga.

En las órdenes castellanas, el tránsito del siglo XIV al XV se realizó con una relativa tranquilidad, fruto de la personalidad y prestigio de los maestres de Santiago, Calatrava y Alcántara; con su desaparición se "reinaugurarán” las injerencias de la monarquía9. Así, cuando a finales de 1404 moría el maestre de Calatrava Gonzalo Núñez de Guzmán, Enrique III de Castilla (1390-1406) quiso que fuese elegido maestre su sobrino el infante Enrique, sin ser freire, aunque no fue un inconveniente. A la muerte de Enrique III, la mayoría de freires de Calatrava eligió como maestre al comendador mayor Luis González de Guzmán en 1407, aunque Enrique siguió con su cargo ${ }^{10}$. En 1414 Benedicto XIII dio por terminado

6. Moreno, 1979 y 1999; Fonseca, 1982; Silva, 1994 y 1997; Mendonça, 1995; Pimenta, 1995, 1997 y 2003; Barbosa, 1998; Costa P, 2004; Mattoso, 2012; Ayala, 2019b; Oliveira, LF, 2019; Repertório Bibliográfico da Historiografia Portuguesa.

7. García Fitz, Novoa, 2018, p. 371.

8. Rodríguez-Picavea, 2007, pp. 714-719.

9. Cabrera, 2000, p. 286.

10. Rades, 1980, Calatrava, ff. 65v-66r. 
el conflicto; el Capítulo volvió a preferir a Luis de Guzmán, al declarar nula la elección de Enrique. Durante siete años hubo pues dos maestres de Calatrava.

Dos de los hijos del regente de Castilla, Fernando el de Antequera, fueron impuestos como maestres: el infante Sancho elegido maestre de Alcántara en 1408, a la muerte del maestre Fernán Rodríguez de Villalobos, -aprovechando la división en la Orden entre el comendador mayor y el clavero- y el infante Enrique en 1409 maestre de Santiago - cambiaría Calatrava por Santiago-, a la muerte de Lorenzo de Figueroa. Al tener Sancho sólo ocho años, actuó como gobernador el comendador Juan de Sotomayor, situado en la órbita clientelar de Fernando ${ }^{11}$. Los dominios de la orden de Santiago, como los de la de Alcántara, eran primordiales para la defensa de la frontera con Portugal. Es lo que indicó el regente a Benedicto XIII, cuando le escribió para convencerle de otorgar el maestrazgo a su hijo Enrique ${ }^{12}$. Lo consiguió en 1410 en detrimento del comendador mayor en Castilla, Garci Fernández de Villagarcía ${ }^{13}$.

En 1443 cuando se disputaba el maestrazgo de Calatrava, entre el clavero Fernando de Padilla y el comendador mayor Juan Ramírez de Guzmán, Juan II (1406/1419-1454) quiso nombrar como maestre al hijo natural del rey de Navarra, Alonso de Aragón, lo que hizo al morir el clavero, maestre electo; se interpretó como el control de la Orden por los infantes de Aragón. Después de Olmedo, Alonso de Aragón tomó las posesiones de Calatrava en la corona de Aragón, se situó en Alcañiz y siguió llamándose maestre. Intentaría volver a Castilla en 1447, pero desde 1445 era maestre Pedro Téllez Girón, hermano de Juan Pacheco ${ }^{14}$. En 1448, Juan II y el maestre Girón ofrecieron a Alonso una importante suma de dinero y de vasallos para terminar su disidencia, por lo que abandonaría sus pretensiones en 1449. No obstante invadiría Castilla en 1450, sin éxito, y renunciaría definitivamente al maestrazgo en 1455 , por una renta anual de quinientos mil maravedíes ${ }^{15}$.

A la muerte de Enrique de Aragón, por las heridas recibidas en Olmedo, fue elegido maestre de Santiago Álvaro de Luna. En 1453, pasó a manos de Juan II, como administrador y a su muerte a las de Enrique IV, antes de dar el maestrazgo al infante Alfonso. Beltrán de la Cueva fue el nuevo maestre en 1464 aunque tuvo que renunciar a él a los cuatro meses y volvió a Alfonso. En 1467 lo fue Juan Pacheco, marqués de Villena. A su muerte, su hijo Rodrigo pretendió sucederle, sin conseguirlo; también lo intentaron el marqués de Santillana y el duque de Medina Sidonia ${ }^{16}$.

11. Rades, 1980, Alcántara, ff. 35r-v; Pino, 1992, p. 165; Corral, 1998, p. 378; Torres, 1999, II, p. 203; Palacios B, 2003b, p. 131.

12. Palacios B, 2003a, I, p. 527, doc. 763, 1409.

13. Suárez, 1960a, pp. 286-287, doc. nº 84; Palacios B, 2003a, I, p. 537, doc. 776, 1410, febrero 5, Barcelona.

14. Solano, 1978, p. 83. Al ser Alfonso de Aragón hijo natural, Juan II y los infantes tuvieron que pedir una dispensa al papa, contando que ya había un antecedente con el maestrazgo de Juan Núñez de Prado en 1313. En septiembre de 1443 Eugenio IV otorgaba la carta de dispensa; Rades, 1980, Calatrava, ff. $71 \mathrm{v}-72 \mathrm{r}$.

15. Rades, 1980, Calatrava, ff. 72r-73r; Cabrera, 1988, pp. 77 y 84-85.

16. Cabrera, 1988, pp. 76-77; Martínez, 2014, p. 63. 
Respecto a la orden del Hospital, después de los intentos por su control en el siglo XIV, a la muerte del prior en 1417 hubo litigios entre los freires y se eligió finalmente a Diego Gómez de Cervantes, pariente del anterior maestre. A partir del reinado de Juan II la monarquía volverá a intentar nombrar a sus priores y consiguió concesiones de los pontífices. El prior Juan de Valenzuela fue fiel a Enrique IV y posteriormente a Afonso V de Portugal. Fue desposeído del cargo y nombrado Álvaro de Stúñiga, hijo del conde de Plasencia ${ }^{17}$.

Los nombramientos de los maestres por los reyes castellanos no siempre fueron bien recibidos, sino que, con frecuencia, los freires fueron contrarios a ellos. Lo podemos observar en la orden de Santiago:

Pero es mucho admirar, a los que este estado de maestre, alcançar desean, que deven entrar por la puerta de la orden, con elección justa i canónicamente fecha, porque este señor maestre -se refieren don Álvaro de Luna- $i$ el dicho señor Ynfante -hablan del infante don Enrique de Aragón-, i don Juan García de Padilla, i el Ynfante don Fadrique, hermano del Rey don Pedro, i don Gomez Suarez de Figueroa, que dicho avemos, i don Martin Barragan, i don Alonso Mendez, sus antecesores, que ovieron la dignidad maestral con mano i favor de los Reyes, fuera de la voluntad y libertad de la orden, todos murieron a fierro, i ovieron los dichos fines ${ }^{18}$.

La ambición de la nobleza por las órdenes iba en contra de ellas mismas, según los mismos autores, refiriéndose a Juan Pacheco: admitió en el ábito asaz personas ynábiles, i dio i proveyó i promutó algunas encomiendas en las contrataciones que tenía con los grandes.

Juan I de Castilla (1379-1390) había conseguido de Clemente VII en 1384 el derecho de designar directamente los maestres de las tres órdenes nacionales, Calatrava, Santiago y Alcántara ${ }^{19}$. Pero el rey no podía pretender hacer lo mismo con las órdenes internacionales como el Hospital, sin duda por la oposición de la Orden al intrusismo de la monarquía aunque logró reivindicar un derecho de injerencia en las encomiendas de sus reinos. En 1421 Juan II de Castilla consiguió de Martín V el reconocimiento de su derecho de nombrar al prior de Castilla, renovado por Eugenio IV en 1440. Además, en 1453 Enrique IV logró de Calixto III ser nombrado gobernador de la orden de Alcántara por diez años. Al año siguiente, el rey era reconocido también como gobernador de la orden de Santiago. De la de Alcántara lo fue solo hasta 1458 pues nombró maestre a su mayordomo Gómez de Cáceres Solís que luego apoyaría al infante Alfonso $^{20}$. En la guerra de sucesión castellana de 1475-1479 se produjeron litigios por el maestrazgo de Alcántara, con la presencia de hasta tres maestres.

El rey portugués João I (1385-1430), que había sido nombrado maestre de Avis en 1364, con solo seis o siete años, colocó como maestres de las órdenes

17. Barquero, 1998, pp. 549-550.

18. Orozco, Parra, p. 375, cit. Rodríguez Casillas, 2013a, p. 50; Orozco, Parra, p. 375, cit. López Fernández, 2017, pp. 155.

19. Suárez, 1960a, p. 16. El texto de la bula pontifical está en pp.163-165.

20. Barquero, 1998, pp. 546-548; Corral, 1998, pp. 379-380. 
nacionales portuguesas a allegados suyos -Fernão Rodrigues de Sequeira en Avis y a Mem Rodrigues de Vasconcelos en Santiago y confirmó también a Lopo Dias de Sousa en Cristo, que ya lo era desde 1373-. En el siglo XV las órdenes serán dominadas en su gobernación por la familia real, lo que maniatará sus libertades y las someterá a la voluntad de la monarquía. En octubre de 1418 el monarca eligió al infante João (1400-1442), condestable de Portugal, administrador de la orden de Santiago, a la muerte de Mem Rodrigues de Vasconcelos; en mayo de 1420 el infante Henrique (1394-1460), duque de Viseu, lo fue de la orden de Cristo; en septiembre de 1434, le llegó el turno al infante Fernando (1402-1443), que lo fue de la orden de Avis, tras la muerte del maestre Fernão Rodrigues, en $1433^{21}$. En 1437 el procurador de la Corona decía que los maestres de Santiago siempre habían sido dos mayores do Regno E afeiçionados aos rreis do portugall.

El único que se quedó fuera de este reparto de los maestrazgos, a parte del heredero D. Duarte, fue el infante Pedro, duque de Coimbra y futuro regente del reino (1438-1448). En 1443, su hijo Pedro, condestable de Portugal, recibió la gobernación del maestrazgo de la orden de Avis y en 1444 Fernando, hermano de Afonso V, la de Santiago; este gobernó también la orden de Cristo a la muerte del infante Henrique.

La Sede Apostólica no respondía siempre favorablemente a las demandas de la monarquía lusa, como se pudo ver cuando se confiscó el maestrazgo de Avis al condestable Pedro, después de Alfarrobeira. En 1461 Pio II entregó la administración de la orden de Cristo a Afonso $\mathrm{V}$, si bien no llegó a tomar posesión de ella. Más tarde, en 1468 el príncipe D. João recibió el gobierno de la orden de Avis y el de la orden de Santiago en 1473, lo que se nos presenta como una estrategia de la Corona de no tener más que un solo mando para ambas órdenes ${ }^{22}$. Las Cortes de Coimbra-Évora pedían que se restringiera el acceso a las órdenes y recomendaban que sus caballeros deberían servir a la Corona en África, como era propio de su religión ${ }^{23}$. Si a mediados del siglo XIV la nobleza ya había penetrado en las órdenes, pues el tercio de los cuarenta y seis comendadores portugueses tenía su origen en la aristocracia urbana, su presencia aún aumentaría en la primera mitad del siglo XV, ya que el $65 \%$ era de origen noble como, por ejemplo, el linaje Vasconcelos ${ }^{24}$.

En cambio, el poder de la monarquía no fue suficiente para conseguir adjudicar a sus familiares directos las dignidades del Hospital de San Juan, orden internacional, pero influyeron para que fuese designado un miembro de linajes cercanos. Primero sería el linaje Ataíde y luego, en 1492, Diego Fernandes de Almeida, gobernador de la casa del hijo bastardo del rey, Jorge -que sería maestre de Santiago y de Avis- y hermano de Pedro da Silva, comendador mayor de Avis. Se cerraba así, por parte de la monarquía portuguesa, el cerco a las órdenes militares lusas.

21. Pimenta, 2000, pp. 91-92; 2001, p. 37, notas 49 y 50; Costa P, 2004, p. 2; Oliveira, LF, 2009, pp.72-74; Oliveira, Monteiro, 2018, II, pp. 200-201 y 222.

22. Pimenta, 2001, p. 49; Fonseca, 2005, p. 205.

23. Almeida, 1967, p. 350.

24. Vasconcelos, 2006, pp. 247 y 252-258. 


\section{GUERRA DE Fronteras. TREguAS y PACES}

Desde el siglo XIV y, en particular, desde la batalla de Aljubarrota en 1385, los reinos de Castilla y de Portugal estaban en guerra: eran algaradas, incursiones en el reino antagónico, en particular en los territorios de las órdenes militares, Santiago y Alcántara en el lado castellano y las de Avis, Cristo, Santiago y el Hospital en el portugués. En el siglo XV, la guerra marcará el clima político y condicionará las relaciones entre ambas potencias ${ }^{25}$.

En Portugal, la región más castigada fue sin duda la de la frontera del Alto Alentejo donde las órdenes tenían señoríos importantes. Los dominios de la orden de Cristo estaban entre Mondego y el Tajo, al haberlos heredado de la orden del Temple, con su sede en Tomar, después de la de Soure ${ }^{26}$. Los de la orden de Santiago con su sede en Alcácer do Sal y en el siglo XV en Palmela, se extendían desde Almada hasta el Algarve, a lo largo del Alentejo atlántico, con un $40 \%$ de las tierras y rentas entre Tajo y Guadiana, $19 \%$ de las de Extremadura y $13 \%$ de las de la Beira. Los del Hospital, además de sus posesiones al norte del Duero, tenían más al sur un núcleo cercano al Tajo, de Belver a Crato y otro al Guadiana, Mourão, Moura y Serpa. Los de Avis se encontraban en el Alto Alentejo, con su centro en Avis, entre Coruche y Elvas -de la orden de Cristo-, con Noudar hasta la Beira Baja ${ }^{27}$.

Enfrente estaban los señoríos de las órdenes castellanas de Alcántara y de Santiago, así como los de los condes de Alburquerque y de Feria. La orden de Alcántara poseía un territorio de unos siete mil quinientos $\mathrm{km}^{2}$, que representaba un $21,17 \%$ de la extensión de Extremadura ${ }^{28}$. La de Santiago ocupaba un espacio que iba desde Montánchez a la tierra de Barros, con una superficie cercana a nueve mil $\mathrm{km}^{2}$. Controlaban pues cerca de un $40 \%$ de la superficie actual de la comunidad extremeña. Estas dos Compañías y las lusas de Avis, Cristo, Santiago y el Hospital verían sus territorios atacados constantemente, al estar en la frontera entre los dos reinos y ser uno de los pasos más utilizados en las incursiones en el reino y el camino hacia Lisboa ${ }^{29}$.

El profesor Monteiro puso de relieve la importancia que la corona portuguesa había dado a la protección de una frontera terrestre luso-castellana con más de mil quinientos kilómetros de extensión, en la que representaban un papel primordial los fronteros y los alcaldes de las fortalezas dispuestas estratégicamente a lo largo de dicha frontera. Ellas y sus guarniciones serán fundamentales en la defensa del territorio y en el control y gestión de las confrontaciones bélicas del período. Por ello, los reyes, la nobleza y las órdenes militares las mantuvieron en perfecto estado de funcionamiento. Así en 1408 João I ordenaba a ciertos conselhos que pagaran al maestre de Avis lo necesario para las obras del castillo de Noudar y

25. Rodríguez Casillas, 2013a, p. 32.

26. Costa P, 2019, p. 196.

27. Mattoso, 1992, p. 531; Fonseca, 2004, p. 123.

28. Pino, 1992, pp. 83-87; Lora, 2008, p. 1597.

29. Costa A, 2016, p. 14. 
Afonso $\mathrm{V}$ también estableció un número importante de ellas en la frontera con Castilla $^{30}$. A mediados del siglo XV se contabilizaban nada menos que cuarenta plazas fuertes en la frontera, de las ciento diecinueve fortalezas en el reino, o sea un $34 \%$. La mitad de los castillos fronterizos estaban en el Alentejo, con los de las órdenes militares ${ }^{31}$.

Para reforzar esas posiciones, durante el reinado de João I se habían multiplicado los coutos de homiziados en lugares fronterizos repoblados por condenados por homicidios y que purgaban y redimían allí sus penas. Desde 1386 se crearon hasta una veintena de esos núcleos defensivos a lo largo de la frontera terrestre con Castilla, desde el Miño hasta el Algarve. Defendían la frontera y participaron en campañas militares, como en la batalla de Alfarrobeira, en $1449^{32}$. En las Cortes de Coimbra-Évora de 1472 se pidió que no se crearan más coutos pues se convertían en covas de ladrões pero Afonso V continuó implantando más, desde $1476^{33}$.

La raya o franja en Castilla disponía de diversas zonas fortificadas en varias líneas escalonadas de castillos e importantes concejos en retaguardia. Una primera era la del Miño, otra entre el Duero y el Tajo, y desde este río a Badajoz, y una tercera desde allí hasta la desembocadura del Guadiana, y que coincidían con las zonas por donde se producían las incursiones en la frontera, entre Duero y Miño, la Beira y entre Tajo y Guadiana, en el Alentejo. Entre el Tajo y Badajoz encontramos los dominios de las órdenes de Alcántara y Santiago y el señorío de Alburquerque, y al sur de Badajoz el del conde de Feria ${ }^{34}$. Por ello, Orozco y Parra decían que si los Reyes Católicos pretendian concentrar sus esfuerzos contra Afonso $V$ en el corazón de Castilla, debian disponer de unas fronteras seguras y bien defendidas:

con las espaldas que tenian seguras por los otros cavalleros e gentes que asy mesmo facían la guerra por las otras partes de la dicha frontera, sus Reales Señorías estaban descargadas de todo lo de estas partes de la dicha Extremadura, i habian buen lugar de proveer $i$ dar remedio en las cosas que tenian entre manos en aquellas partes de Toro i Çamora, donde estaba el dicho adversario ${ }^{35}$.

Francisco García Fitz incide en que los daños en la frontera no eran sino el intento de lograr una serie de objetivos estratégicos; João Gouveia Monteiro señala igualmente la importancia de la frontera desde el punto de vista estratégico y táctico en las guerras luso-castellanas, en la perspectiva portuguesa ${ }^{36}$.

La frontera era pues controlada y defendida por de los fronteros que eran escogidos entre los miembros de la alta nobleza o incluso de la casa real. Así, por ejemplo, Diogo Lopes de Sousa era frontero en Aronches y Elvas en 1441, Sancho

30. Oliveira, 1987, p. 346; Monteiro, 2000, pp. 137-139; Fonseca, 2000, p. 662, nota 17.

31. Monteiro, 2000, pp. 142-143.

32. Moreno, 1980, I, pp. 368-369; Monteiro, Martins M, 2010, p. 26; Oliveira, Monteiro, 2018, p. 200.

33. Ventura, 1998, pp. 602 y 608.

34. Pino, 1987, p. 387; Martín, 1994, pp. 29-31; Castrillo, 1997, II, pp. 535-536.

35. Orozco, Parra, 2017, cit. Rodríguez Casillas, 2017, p. 287.

36. García Fitz, 1998b, pp. 76-119; Monteiro, 2000, p. 145. 
de Noronha era frontero en Estremoz en 1442, Martim Afonso de Melo lo era en Olivença en 1449. En el inicio efectivo de su reinado, Afonso V (1448-1479/1481) nombró como fronteros en el Alentejo a su hermano Fernando y entre Miño y Duero a su tío el duque de Braganza. Haría lo mismo en 1471 con el duque João de Viseu, al que nombraría frontero mayor entre Tajo y Guadiana y el reino del Algarve y pedía a la orden del Hospital que le obedeciese; en 1489 y en la misma frontera lo sería el duque Manuel de Beja y Viseu, futuro rey. Estos fronteros, disponían de unos efectivos de entre cien y doscientas cincuenta lanzas. Así D. Duarte había pagado cien reales mensuales a doscientos vasallos para que estuviesen constantemente preparados con caballos y armas ${ }^{37}$.

En Castilla lo serían los maestres de las órdenes de Alcántara y de Santiago y el conde de Feria ${ }^{38}$. Este disponía de una fuerza formada por trescientos hombres a caballo y tres mil a pie, que se podía ampliar en caso de necesidad. La orden de Santiago podía llegar a tener ochocientas lanzas y un número sin definir de peones y el maestre Cárdenas alcanzará las mil lanzas. Alcántara, en su proliferación de maestres, presentaba con F. Solís doscientos caballeros y cuatrocientos infantes y A. Monroy peleaba con unos efectivos entre doscientas y quinientas lanzas y trescientos y cuatrocientos peones. Los Stúñiga reunirían ochocientos caballeros y dos mil infantes en el cerco de Alcántara. En Badajoz el rey mantenía una fuerza de cien hombres a caballo, prestos a hacer la guerra en la frontera y un hombre poderoso como frontero, con mucha gente ${ }^{39}$.

En época medieval no había ejércitos permanentes; el rey convocaba a sus vasallos para cubrir sus exigencias guerreras. En las Cortes de Guadalajara de 1390, se instauró un sistema de alardes, esperando establecer un ejército armado y disponible ${ }^{40}$. Según M.A. Ladero, en el período de 1478-1489, las cuatro órdenes militares suministraban dos mil trescientos jinetes, de quinientos a seiscientos ballesteros, dos mil cuatrocientos lanceros y trescientos veintiséis espingarderos. En 1495, el número de lanzas que la orden de Alcántara puso a disposición de los reyes era de ciento cuarenta y dos, lo que presupone que la cifra debió de ser de ese orden a lo largo del siglo XV -entre unos cuatrocientos a quinientos jinetes y peones-, salvo en casos especiales como en la guerra de Granada ${ }^{41}$. João I había definido que la monarquía portuguesa debía tener una fuerza armada permanente de tres mil doscientas lanzas, repartidas entre la nobleza y las órdenes militares: quinientas de la alta nobleza, dos mil trescientas sesenta de la pequeña nobleza y trescientas cuarenta de las órdenes militares ${ }^{42}$.

37. Costa P, 2000, p. 221; Silva, 2002, p. 95; Marques, 2009, p. 113; Monteiro, Martins M, 2010, p. 31 .

38. Monteiro, 1998b, p. 38; 2000, p. 140; Montaña, 2008a, p. 17.

39. Palencia, 1908, II, pp. 69 y 225; Maldonado, 1978, p. 118; Ventura, 1998, p. 605; Lora, 2000, p. 187; Rodríguez Casillas, 2013b, p. 87.

40. García Fitz, 2007, pp. 154-156.

41. Ladero MF, 1982, p. 501; Ladero, 1993, p. 162.

42. Monteiro, 1998b, p. 81 . 
La lanza era una unidad militar relacionada con la organización de las órdenes militares castellanas ${ }^{43}$. La lanza hispánica estaría integrada como mínimo por un caballero, equipado como caballería pesada, acompañado por otra montura ligera y de uno a tres ayudantes. En Portugal, a cada "lança" correspondía un hombre de armas ${ }^{44}$. En Castilla, en el siglo XV, la composición de la "lanza” dependía de las aportaciones de los maestres y comendadores, según el tamaño de la institución. Varias monturas y varios auxiliares acompañaban a "hombres de armas" y "jinetes", entre ellos lanceros y ballesteros que incluso podían ir a caballo ${ }^{45}$.

Una vez definidos los espacios, los contendientes y su composición, ¿cuáles fueron los hechos que sucedieron en las relaciones castellano-portuguesas? A finales del siglo XIV, se habían producido treguas en medio de las negociaciones de paz, como las de Morão en 1389 y las de Lisboa en $1393^{46}$. Aunque en mayo de 1396 los portugueses tomaban Badajoz, el almirante Diego Hurtado de Mendoza recorrió las costas hasta Lisboa y, en apoyo del infante Juan, Ruy López Dávalos entraba hasta Viseu y, al mismo tiempo, el maestre de Santiago penetraba en tierras entre Tajo y Guadiana, por Beja, Moura, Serpa y el Campo de Ourique; en diciembre el condestable Pereira llegaba hasta Cáceres. En 1397 tropas castellanas de Santiago y Alcántara entraban en Portugal, por lo que se consideró que las treguas estaban rotas y se siguió negociando, hasta los acuerdos de Villanueva de Bancarrota en 1399. De todos modos, los nobles reunidos en Cortes en Toledo en 1406 consideraban al rey de Portugal digno de poco crédito en la conservación de las treguas ${ }^{47}$. Era la táctica de los reyes de multiplicar las apariciones de tropas en la frontera, para ejercer una presión en el reino enemigo y condicionar esas conversaciones. Mostraban así que controlar el espacio y el adversario era también, o sobretodo, controlar la frontera que los unía y desunía ${ }^{48}$.

Seguirían las cabalgadas en 1400, como en Crato y en Valencia de Alcántara. Por una carta del maestre de Santiago a Enrique III conocemos las incursiones de las órdenes de Santiago y del Hospital, en agosto sobre la fortaleza de Noudar ${ }^{49}$. En fechas cercanas a 1401, la reina Catalina de Lancaster planteaba a Enrique III la posibilidad de conseguir la paz entre los reinos de Castilla y de Portugal al retirar el apoyo a la reina Beatriz a cambio de una reconciliación con João I;

43. Ayala, 2003, pp. 555-557; Rodríguez-Picavea, 2008, pp. 139-140; Palacios S, 2018a; Boix, 2020, pp. 42-43.

44. Monteiro, 1998 b, p. 34, nota 37.

45. Ladero, 2009, pp. 231 y 255, cit. Palacios S, 2018, pp. 302-303.

46. Suárez Bilbao, 1994, p. 83. Unas treguas por quince años, con la liberación de los prisioneros sin rescate, la devolución de dos villas portuguesas, la elección de rehenes y la obligación por parte castellana de no dar apoyo a la reina Beatriz y a los dos hijos de Inés de Castro y de Pedro I: Dinis y Juan. Se nombraron "conservadores de la tregua" extendidos a lo largo de la frontera, como garantes de la justicia por daños en las incursiones. Por parte portuguesa, lo fueron Nun Álvares Pereira, los maestres de Santiago y de Cristo y el prior del Hospital. Este custodió los rehenes castellanos en el castillo de Santarem.

47. González, 2013, p. 135.

48. Monteiro, 2000, pp. 148-149.

49. Suárez, 1960b, doc. 29. 
propuesta que no gustó al rey y no mostró ningún entusiasmo por su causa ${ }^{50}$. En el armisticio o treguas por once años de Segovia de 1402, el maestre de Santiago Lorenzo Suárez Figueroa fue el encargado de recibir Badajoz, dentro de la restitución recíproca de núcleos poblacionales y de rehenes castellanos, entre los que se encontraba su primogénito Gome. Así mismo, firmaba esas treguas el maestre de Avis Lopo de Sousa ${ }^{51}$.

Durante la regencia de Juan II por Catalina de Lancaster y de Fernando el de Antequera, se avanzaron las negociaciones de paz con Portugal, por la firme voluntad de la reina, complicado por la presencia e influencia de portugueses en la corte castellana, como la reina Beatriz ${ }^{52}$. No sólo tenían dudas los regentes, sino también la nobleza ya que había perdido a miembros de sus linajes; había participado en negociaciones anteriores; tenían posesiones en la frontera o había protagonizado enfrentamientos con los portugueses, como el maestre de Santiago Lorenzo Suárez de Figueroa, que había recibido de Enrique III, Feria, Zafra y La Parra, como recompensa por su lucha contra Portugal ${ }^{53}$. Se firmó finalmente una tregua en 1406, otra cerca de Ciudad Rodrigo en 1407, preludio del acuerdo que se refrendó en octubre de 1411 en Ayllón y que puso fin a más de cuatro décadas de litigios y disputas entre los dos reinos. Se pretendía que Aljubarrota fuera ya cosa del pasado. Era un avance importante para la normalización de las relaciones entre Castilla y Portugal ${ }^{54}$.

El rey João I había intentado en 1418 otro acercamiento a Castilla mediante el compromiso de la infanta Isabel de Avis con el futuro rey Juan II, sin resultados. Este, una vez alcanzó el poder en 1420, preparó la guerra contra Portugal pero la llegada al gobierno de Álvaro de Luna iba a cambiar las posiciones. Así, los pactos de 1411 fueron al fin ratificados en Ávila por Juan II el 30 de abril de 1423 y por João I en Sintra el 4 de septiembre. La guerra no volvió antes de $1475^{55}$.

En el lado castellano, la orden de Calatrava se puso de parte del infante Enrique, maestre de Santiago en 1419, en los problemas con el monarca, pero en 1421 el maestre Luis González de Guzmán estaba con Juan II en Montalbán y participó en su Consejo. Lo mismo ocurrió con el maestre de Alcántara Juan de Sotomayor, que estuvo en las cortes de Palencia de 1429 como uno de los Grandes de Castilla y sin embargo apoyó a los infantes Enrique y Juan al llevar sus tropas a Olme$\mathrm{do}^{56}$. Estos conflictos desplazaron la discordia a la frontera castellano-portuguesa al refugiarse Enrique en los dominios extremeños de la Orden, lo que propició enfrentamientos con parte de la nobleza de la región y con la orden de Alcántara aunque los infantes Enrique y Pedro tenían el apoyo del maestre Sotomayor. El

50. Novoa, Fernandes, 2006, p. 74.

51. Silva, 2002, p. 56; Oliveira, Monteiro, 2018, p. 194.

52. González, 2013, pp. 135-140. Beatriz medió entre Fernando y el comendador mayor de Castilla de la orden de Santiago, Garci Fernández de Villagarcía, por la cuestión del maestrazgo de la Orden.

53. Mazo, 1980, pp. 74-75, 137 y 305-306.

54. Novoa, Fernandes, 2006, pp. 77 y 154, nota 129; González, 2013, p. 147.

55. Oliveira, Monteiro, 2018, p. 194.

56. Rades, 1980, Alcántara, f. 37r; Torres, 1999, II, p. 264; Rodríguez-Picavea, 2005, p. 106. 
sobrino de este, Gutierre de Sotomayor, en 1432 detuvo al infante Pedro en un intento de cambiar la política de la Orden, lo que trajo la división en la milicia.

El maestre de Alcántara Juan de Sotomayor quedó como frontero y capitán general entre Valencia de Alcántara y Badajoz; allí, en 1429-1432, mandó a los ejércitos de Juan II frente al infante Enrique de Aragón, en la campaña de Alburquerque con unas tropas de trescientos hombres de armas, noventa jinetes y doscientos peones $^{57}$. El maestre pasaba fácilmente de servir al rey a hacerlo con los infantes Enrique y Pedro, por lo que se le tildó de dudosa fidelidad al primero. Desde 1432, se produjeron diversas tentativas de paz, que culminaron con la elección efectiva como maestre de Alcántara de Gutierre de Sotomayor y con la huida, en 1433, a Portugal de Enrique, de Pedro -liberado por Juan II- y de Juan de Sotomayor, camino de la península itálica en donde estaba Alfonso V de Aragón (1416-1458) ${ }^{58}$.

En estos años, Portugal, que desde las paces de Ayllón de 1411, había querido establecer una paz definitiva con Castilla que le permitiera blindarse frente al temor de un acercamiento entre Castilla y Aragón que, quizás, tuviesen ansias de expansión peninsular, de invadir Portugal y de unificar así los territorios. Al fin, el 30 de octubre de 1431 se firmaron unas paces perpetuas entre Portugal y Castilla en Medina del Campo, ratificadas en enero de 1432 en Almeirim. Esas paces buscaban establecer una fase de prosperidad dominada por el entendimiento y las relaciones cordiales. Y, en cierto sentido, ese objetivo se logró sin demasiados esfuerzos. Almeirim fue realmente un tratado definitivo en las relaciones entre Portugal y Castilla en el siglo $X V^{59}$.

En 1433 moría João I y le sucedía su hijo Duarte (1433-1438). En su reinado se produjo el asalto fallido a Tánger, en donde resultará preso su hermano el infante Fernando, maestre de Avis, que murió en reclusión. Con el fallecimiento del rey Duarte se inició la crisis sucesoria, por la minoría de edad del infante Afonso, entre la reina viuda Leonor, hija de Fernando I de Aragón y el infante D. Pedro (1438-1448), que sería regente del reino. La orden de Cristo, en manos del infante Henrique, nombrado fronteiro mor en la Beira, y la de Santiago, gobernada por el infante João, nombrado fronteiro mor en Entre-Tejo-e-Guadiana, apoyaron a D. Pedro ${ }^{60}$. Leonor tuvo que huir a Crato, sede de la orden del Hospital, cuyo prior Nuno Gonçalves de Góis se exilió en Castilla y en Aragón pues sería embajador de Alfonso V ante el Gran maestre de Rodas, en $1458^{61}$. D. Pedro se apoderó de Crato en 1441.

El regente Pedro de Portugal fomentó la amistad con Juan II de Castilla y con el condestable Álvaro de Luna a los que apoyó contra los infantes de Aragón: el rey Juan de Navarra y Enrique maestre de Santiago; las órdenes militares castellanas también intervendrán en este conflicto. Entre 1420 y 1440 no hubo enfrentamientos entre Castilla y Portugal ya que la monarquía castellana estaba ocupada

57. Rodríguez Casillas, 2019, pp. 247-267.

58. Palacios B, 2003, pp. 151 y 154.

59. Romero, 2007, p. 65; Montaña, 2014, p. 899.

60. Moreno, 2000, p. 790.

61. Costa P, 2000, pp. 204-206; Oliveira, Monteiro, 2018, pp. 218-219. 
en sus luchas internas como para asumir otros litigios; ocurriría lo mismo con las órdenes militares. Al final del periodo, un nuevo incidente resucitaba las escenas de guerra, como declaraban los pobladores de Mourao en $1439^{62}$.

En la década siguiente, esa armonía entre Castilla y Portugal se vería comprometida por la victoria política de los infantes de Aragón en Castilla, por lo que el regente D. Pedro empezó a reclutar hombres por si fuera necesaria una intervención. A finales del verano de 1441 anotamos la primera actuación militar portuguesa, después de la derrota de Álvaro de Luna en Medina del Campo por los infantes, en tierras de la orden de Santiago, comandada por el frontero Duarte de Meneses ${ }^{63}$. En 1443 el infante Enrique, de vuelta a la obediencia del rey, partía hacia Andalucía para ocupar fortalezas de la orden de Calatrava en un momento en que había gran disputa por el maestrazgo, entre el clavero y el comendador mayor ${ }^{64}$. Entre marzo y abril de 1444, un segundo contingente portugués, bajo el mando del maestre alcantarino Gutierre de Sotomayor, defendió Sevilla y atacó Alcalá de Guadaira y Carmona, plazas santiaguistas del infante Enrique ${ }^{65}$. En mayo de 1445, se produjo una tercera intervención lusa; esta vez mandada por D. Pedro, hijo del regente, maestre de Avis y condestable de Portugal desde 1443, -sería el segundo rey intruso (1464-1466) en Aragón en la guerra civil catalana-. Se desplazó a Castilla en respuesta a la demanda de ayuda cursada por Juan II, en el enfrentamiento contra los infantes de Aragón en la primera batalla de Olmedo. Llegó cuando el rey de Castilla había vencido y fue recibido por Gutierre de Sotomayor. En las huestes reales estuvieron las órdenes de Calatrava, de Alcántara y del Hospital; la de Santiago dividida según su obediencia ${ }^{66}$.

\section{LAS RELACIONES DESPUÉS DE LA BATALla DE OLMEDO}

Este combate y la renuncia de los infantes de Aragón a más intervenciones en Castilla favorecieron que el regente D. Pedro y Álvaro de Luna propusieran el matrimonio de Juan II y de la infanta Isabel, hija D. João, hermano del regente portugués y que fuera administrador de la orden de Santiago. La derrota de D. Pedro en Alfarrobeira en 1449 y el acceso al poder del rey Afonso V cambiaron el escenario. Antes, de las heridas recibidas en Olmedo, Enrique había muerto en Calatayud en junio de 1445, por lo que se había elegido a Álvaro de Luna como maestre de Santiago que ya la administraba desde 1429, cuyo hecho consolidó su presencia en tierras extremeñas. El maestre alcantarino Gutierre de Sotomayor aumentaría igualmente sus dominios ${ }^{67}$.

62. Moreno, 1997, p. 10.

63. Monteiro, 1998b, p. 529; Oliveira, Monteiro, 2018, p. 222.

64. Rades, 1980, Calatrava, f. 71r; García Fitz, Novoa, 2018, pp. 365-366.

65. Rades, 1980, Santiago, ff. 43r.

66. Rades, 1980, Alcántara, f. 43r; Crónica de Juan II, II, p. 628; Torres, 1999, II, ff. 324-325.

67. Rades, 1980, Santiago, f. 61r. 
Álvaro de Luna en 1453 perdió los favores del rey, en parte debido a su política portuguesa. El rey Juan II administraría las órdenes de Santiago y de Alcántara tras la muerte de Luna y de Sotomayor. Llegaría el ascenso, ya como privado del príncipe Enrique, de otro hombre ambicioso, Juan Pacheco, de linajes portugueses exilados en Castilla después de Aljubarrota. En 1454 se produjo la muerte del monarca y el acceso al trono de Castilla de Enrique IV, así como su enlace en 1455 con Juana de Portugal, hermana de Afonso V. Pacheco será marqués de Villena y maestre de Santiago en 1467, como su hermano, Pedro Téllez Girón, lo será de Calatrava $^{68}$.

En los conflictos entre Enrique IV y el bando nobiliario promovido por Juan II de Aragón, Afonso V de Portugal apoyó inicialmente a este último, traducido en el enlace previsto entre el príncipe de Viana y Catalina, hermana del rey de Portugal. Estos acuerdos se rompieron en 1461, a la muerte de Carlos de Viana. Enrique IV aceptaría ser rey de Aragón ${ }^{69}$. En 1462 Beltrán de la Cueva era nombrado maestre de Santiago por pocos meses ya que pasó al infante Alfonso, cuyo regente fue su tutor Juan Pacheco ${ }^{70}$. En 1458 había sido nombrado maestre alcantarino Gómez de Cáceres Solís que en 1463, junto al prior del Hospital Juan de Valenzuela, acompañó a Enrique IV en las vistas con Luis XI con objeto de arbitrar la guerra civil catalana y las diferencias con la orden de Calatrava en Aragón ${ }^{71}$.

Los últimos años cuarenta del Cuatrocientos portugués estuvieron marcados por el fin de la regencia de D. Pedro, por su derrota en Alfarrobeira en 1449, por la ascensión al trono portugués de Afonso V (1438/1449-1481) y por el proyecto político de la monarquía lusa en una estrategia pro-castellana, que llevaría a una alianza con Castilla y que debía culminar con el matrimonio citado de Enrique IV y la infanta lusa Juana. En la década siguiente las relaciones entre los dos reinos se complicaron con la emisión de las bulas de Nicolás V en 1452, Divino amore communiti y en 1455 Romanus pontifex, por las que establecía de facto un monopolio portugués en las navegaciones más allá del cabo Bojador, confirmadas por Calixto III $^{72}$. A pesar de ello, se estableció el tratado de Elvas en 1456 como política de mutuo apoyo. Desde 1457 la orden de Cristo dirigió sus miras hacia África y, después de la conquista de Alcácer Ceguer, se le otorgó el derecho de patronazgo de ella.

En el inicio activo de su reinado, Afonso V empezó a efectuar nombramientos, como el de su tío el duque de Braganza como frontero entre Miño y Duero. Despojó del maestrazgo de la orden de Avis a D. Pedro, condestable del reino e hijo del regente derrotado, y fue gobernador interino el infante Henrique. D. Fernando, hermano menor del rey, fue nombrado frontero en el Algarve y en el Alentejo y condestable del reino, y se lo retiró a Pedro, que se refugió en Castilla. Este volvió a ser maestre de Avis en 1453, regresó a Portugal en 1456 y siguió como

68. Rades, 1980, Santiago, f. 65r; Romero, 2003, p. 192.

69. Zurita, 2007, libro XVII, cap. XLV, p. 432.

70. Rades, 1980, Santiago, f. 64r; Pino, 1992, p. 207.

71. Torres, 1999, II, ff. 353-354.

72. Silva, 2002, pp. 76-78. 
maestre cuando las autoridades catalanas le ofrecieron el título de rey de Aragón (1464-1466) ${ }^{73}$. Por ello encontramos en Cataluña a caballeros y tropas de Avis que estaban en Ceuta con D. Pedro y le acompañaron a Barcelona. En 1455 Afonso V designaría prior del Hospital a Vasco de Ataíde, uno de los padrinos del futuro João II $^{74}$. A la muerte del infante Henrique en 1460, el infante Fernando, maestre de Santiago, recibió también la administración de la orden de Cristo $^{75}$.

La muerte de D. Pedro en 1466 representó no solo el final de la posible implantación de una dinastía portuguesa en Aragón, sino también la renuncia a la presencia de Portugal en el Mediterráneo occidental. La monarquía lusa quiso recuperar la gobernación de la orden de Avis y tuvo como administrador al futuro João II (1477/1481-1495), gracias a la bula Cessant Nuper de Paulo II de septiembre de 1468, culminada por el capítulo de la Orden en enero siguiente ${ }^{76}$. Estos eventos contribuyeron a centrar la orientación definitiva de la política y de la diplomacia portuguesa hacia Castilla por la buena sintonía entre Afonso V y Enrique IV. Ambos reyes se habían entrevistado a primeros de 1464 en Gibraltar, y Enrique le propuso al rey portugués matrimonio con su hermana Isabel y también el de su hija Juana con el heredero João ${ }^{77}$. Lo que interesaba era una eventual unión de los dos reinos, aunque hubiese dudas sobre la viabilidad de tal proyecto.

\section{LA GUERRA CIVIL CASTELLANA}

El nacimiento de la infanta Juana, el ascenso de Beltrán de la Cueva y el desplazamiento de Juan Pacheco y de sus partidarios propiciaron un cambio en los apoyos de la nobleza, con los Mendoza en el bando del rey y con la oposición de la Liga nobiliaria, que desarrolló una campaña de deslegitimación de la infanta. La Liga tomó al infante Alfonso como emblema de su programa de control de la monarquía con el pretexto de la cuestión hereditaria. En septiembre de 1464 publicó un manifiesto en el que decían defender los derechos del infante contra la pretensión de Enrique de sostener la herencia de Juana. Enrique IV negoció con los rebeldes y reconoció a Alfonso como heredero, con el compromiso de casarse con Juana, pero no transigió sobre la autoridad de la monarquía. Ello llevó a la farsa de Ávila en junio de 1465 con la deposición de Enrique y la proclamación como rey de Alfonso. Era una verdadera guerra civil, que se prolongó durante quince años y que sería calificada como aventura política sin salida ${ }^{78}$.

73. Fonseca, 1972, pp. 53-59; Vicens, 2003, pp. 287 y 290; Zurita, 2007, libro XVII, cap. LIII, p. 463 .

74. Costa P, 2000, p. 210; Oliveira, Monteiro, 2018, pp. 250-252.

75. Vasconcelos, 2012, p. 90

76. Fonseca, 1983, pp. 28-31; Vasconcelos, 2012, p. 84

77. Oliveira, Monteiro, 2018, p. 262.

78. Bernaldez, 1962, p. 28; Torres, 1999, II, ff. 370-371; Romero, 2002, p. 197; 2003, p. 188; Lora, 2008, p. 1627. 
Las órdenes militares castellanas se vieron encuadradas en uno u otro bando en esas contiendas. Su actuación ha sido analizada por los profesores García Fitz y Novoa, en particular sobre los efectivos de sus huestes y su racionalización ${ }^{79}$, por lo que nos limitaremos a indicar aquello que se relacione con Castilla y Portugal, así como lo referente a los territorios de frontera o próximos a ella. Pues, una parte de la lucha que se libra en Extremadura se hace por alcanzar la provisión de los maestrazgos de Alcántara y Santiago y la participación de los principales linajes en ella ${ }^{80}$.

En 1466 se vislumbraba una alianza entre Castilla y Portugal, mediante el compromiso de Afonso V con la infanta Isabel, lo que preocupaba a los líderes de la Liga. El maestre Girón aseguraba a Enrique IV la lealtad de Calatrava y ponía a su disposición tres mil lanzas y un préstamo de setenta mil doblas; pedía a cambio la suspensión de los acuerdos con Portugal y la mano de Isabel, a lo que se avino el rey. El maestre viajó a Madrid para el desposorio, pero falleció antes de llegar ${ }^{81}$. En agosto de 1467 se produjo la segunda batalla de Olmedo en la que vencieron los partidarios de Enrique IV y se volvió a la solución anterior: Alfonso como heredero y su matrimonio con Juana. La muerte de Alfonso el 5 de julio de 1468 vino a perturbar ese proyecto; Isabel se declaraba heredera y llegaron los acuerdos de Guisando. Ahora, Enrique IV retomaba la idea de unir a Afonso V e Isabel. Pero, esta decidió otro destino: se casó en Valladolid, en octubre de 1469, con Fernando de Aragón.

Mientras tanto, en la frontera, el maestre de Alcántara Gómez Solís y el clavero Alonso de Monroy, enemistados por cuestiones personales desde $1464^{82}$, se habían enfrentado en Coria en 1466-1467, mientras las tropas de los Stúñiga vigilaban el cerco, en una intervención que podría percibirse como un apoyo dado al maestre al ser uno de los nobles que defendían los derechos del príncipe Alfonso. Podría interpretarse también como el deseo de los Stúñiga de participar en las luchas internas de una orden militar cuyo posible control abriría nuevos horizontes políticos y económicos a su linaje ${ }^{83}$.

El litigio por el maestrazgo de Alcántara aún existía en 1468, después de fallecer el príncipe Alfonso. Ciertos nobles, como los Stúñiga, apoyarían al rey Enrique, lo que se tradujo en desencuentros entre los condes de Plasencia y el maestre Solís, partidario de Isabel, y que fueron aumentados por las intromisiones de aquellos en el maestrazgo; esa ruptura fue aprovechada por Monroy para enfrentarse al maestre. Los condes fueron beneficiados a finales de 1469 con el ducado de Arévalo. En ese año en Trujillo el maestre Solís y el clavero Monroy pidieron perdón a Enrique IV $^{84}$.

79. García Fitz, Novoa, 2018.

80. Pino, 1987, p. 394; 1992, p. 224.

81. Rades, 1980, Calatrava, f. 76v-77r.

82. Lora, 2003, p. 168.

83. Torres, 1999, II, f. 375; Lora, 2008, p. 1629.

84. Rades, 1980, Alcántara, ff. 45v-46r; Lora, 2003, p. 174; 2008, pp. 1630-1632. 
La actividad del clavero en contra del maestre fue grande en esos años, atacando diversos territorios de la Orden ${ }^{85}$. En 1470, Monroy ganó la batalla del Cerro de las Vigas a Solís, utilizando la misma táctica que los portugueses en Aljubarrota ${ }^{86}$; se depuso al maestre y se le comunicó al papa Paulo II que nombró gobernador de la orden a Alonso de Monroy, pero Solís no se resignó y siguió en su cargo ${ }^{87}$. Ya entonces eran claras las intenciones de los Stúñiga sobre la orden de Alcántara y que se confirmaron en 1472, pues en febrero la duquesa de Arévalo se dirigió al papa Sixto IV para que se reservase la provisión del maestrazgo para su hijo Juan $^{88}$. Como describe Antonio de Nebrija, el empeño de los Stúñiga en conseguir el maestrazgo fue una lucha-titánica en muchas ocasiones-, con grandes episodios bélicos y pequeñas escaramuzas ${ }^{89}$.

A pesar de ello, en octubre Alonso de Monroy se hizo elegir maestre de Alcántara y siguió la lucha contra el maestre Gómez Solís. A la muerte de éste en 1473 Monroy fue apresado por hombres del maestre de Santiago en Magacela ${ }^{90}$. A pesar de que se había hecho designar como maestre un sobrino del maestre Solís, Francisco Solís el Electo, imperó la voluntad del papa Sixto IV quien nombró maestre a Juan de Stúñiga por una bula de abril de 1474. Por no tener la edad, su padre Álvaro fue administrador de la Orden; Juan recibiría los hábitos en 1475. Mientras, Solís adoptó el partido de los reyes de Sicilia. Hubo pues durante un largo periodo dos y tres maestres de Alcántara, con la Orden dividida.

En el período de 1464-1474, no hubo enfrentamientos entre portugueses y castellanos, por la amistad entre los dos soberanos y los problemas internos en Castilla ya que no les permitían desviar su atención, sus recursos y sus esfuerzos en otras direcciones. Es lo que sucedió con las órdenes militares que apoyaron a un bando o a otro de la política castellana, según sus intereses o los de los maestres, en función de sus ambiciones y de sus parcialidades. De hecho,

los enfrentamientos en el interior de esas milicias tenian sus causas en el marco de la contienda general, pero respondían también a la resistencia de estas instituciones a su privatización por parte de los maestres y de la nobleza. Así, no es casual que en buena parte de estos enfrentamientos, la mayoría de comendadores y freires se posicionaran casi siempre en contra de sus respectivos maestres y obviamente de sus linajes nobiliarios y a favor de los monarcas y el papado, que casi siempre se opusieron a la patrimonialización de estas instituciones por parte de la nobleza ${ }^{91}$.

Enrique IV falleció a finales de 1474 y accedió al trono Isabel (1474-1504). También había muerto Juan Pacheco y, a pesar de las reivindicaciones de su hijo Diego, marqués de Villena, sobre el maestrazgo de Santiago, se formó un dúo en

85. Rodríguez Casillas, 2013b, pp. 54-55.

86. Monteiro, 2001, pp. 206-213.

87. Torres, 1999, II, ff. 401-403.

88. Rades, 1980, Alcántara, pp. 49v-50r; Torres, 1999, II, ff. 407-408.

89. Lora, 2003, p. 163.

90. Rades, 1980, Alcántara, ff. 49r-v.

91. García Fitz, Novoa, 2018, p. 380. 
la cabeza de la Orden con los comendadores mayores, Alonso de Cárdenas en León y Rodrigo Manrique, conde de Paredes, en Castilla; cada uno se ocuparía de sus territorios. No todos acatarían ese reparto, pues otros nobles pretendían el maestrazgo, como el duque de Medina Sidonia o el conde de Feria. Este se enfrentó en enero de 1475 con Cárdenas, que le venció en Jerez de los Caballeros. El duque de Medina Sidonia salió de Sevilla con intención de invadir los territorios de Santiago con dos mil de a caballo y a quien se le uniría el conde en Mérida. Cárdenas salió de Llerena con ochocientas lanzas y muchos peones y los derrotó en Guadalcanal ${ }^{92}$.

\section{LA GUERRA DE SUCESIÓN CASTELLANA}

Podemos considerar que la guerra de sucesión fue una continuación de la guerra civil, ya que la

guerra que aflige al reino de Castilla entre 1475 y 1479 tiene como objetivo único aparente dirimir la sucesión de Enrique IV, entre doña Juana, la excelente señora, e Isabel. En realidad, es un conflicto de hondas raices en torno a la forma en que el monarca ejercerá el poder: por sí mismo, como verdadero dueño de aquél, o como mero instrumento del Consejo, a su vez simple portavoz de una parte de la nobleza. La última fase de la guerra, aunque era evidente con anterioridad, adquiere el carácter de un enfrentamiento entre Portugal y Castilla ${ }^{93}$.

La nobleza se decantó por uno u otro bando. Uno de los primeros nobles que optó por Isabel fue García Álvarez de Toledo, duque de Alba, que se mantuvo firme en sus apoyos a lo largo del conflicto. Otros, como Beltrán de la Cueva, se inclinarían hacia uno u otro bando según el desarrollo del conflicto, por lo que serían acusados de doble juego ${ }^{94}$.

Afonso V se embarcaría en otra aventura ibérica, al alentar el acceso al trono castellano de su sobrina Juana, con la que pretendía casarse. Era lo que "legitimaría" su intervención y permitiría la implantación de su proyecto hegemónico sobre la Península Ibérica. En abril de 1475 se supo que Afonso V había aceptado dicho matrimonio y se alió con el bando de Diego Pacheco, con los Stúñiga, con el arzobispo Carrillo y con Rodrigo Girón, entre otros ${ }^{95}$. Reunió a su consejo en Estremoz que estaba dividido en cuanto a la decisión a tomar: el heredero portugués D. João, gobernador de Avis y Santiago, era partidario de la campaña castellana; ciertos nobles como el duque de Guimaraes no lo eran; el prior del Hospital Vasco de Ataíde dudaba por la falta de previsiones sobre los medios a poner en obra. La

92. Bernaldez, 1962, pp. 86-90; Pulgar, 2008, 1, pp. 58-60 y 79-80; Rodríguez Casillas, 2013a, pp. 51-52, 57, 97-99 у 138.

93. Álvarez Palenzuela.

94. Lora, 1998, pp. 387-389.

95. Pulgar, 2008, 1, pp. 83-95. 
orden de Cristo estaba en manos del duque de Viseu, menor de edad, que seguía al monarca ${ }^{96}$. Los reyes de Castilla disponían del apoyo del conde de Feria, al que dieron el mando militar de la frontera meridional, el del duque de Medina Sidonia al que encomendaron la defensa del reino de Sevilla, así como el del comendador mayor de Santiago, Alonso de Cárdenas y el del maestre "electo" de Alcántara, Francisco Solís ${ }^{97}$.

El 10 de mayo el rey portugués invadió Castilla por Alburquerque, con tres mil quinientos caballos e muchissima gente de a pie y fue recibido en Plasencia por sus partidarios. El 30 se celebraba el desposorio pendiente de la dispensa papal y se proclamaban reyes de Castilla; de ahí pasaron a Arévalo, lugares de los Stúñiga. En marcha hacia Burgos, ganaron en septiembre la batalla de Baltanás a los leales a los reyes castellanos. A la vista del poco apoyo recibido en Castilla, Afonso V marchó hacia Toro y Zamora, limítrofes con Portugal ${ }^{98}$. Los nobles castellanos adeptos de Afonso V no lo pudieron ayudar ya que la posición del maestre calatravo se vio debilitada al abrazar el partido de los reyes de Castilla el comendador mayor Fernán Gómez de Guzmán y el clavero García López de Padilla. Junto a Rodrigo Manrique combatieron en las tierras del maestre de Calatrava y del marqués de Villena y tomarían Villa (Ciudad) Real y los territorios dependientes ${ }^{99}$.

Como había ocurrido en la guerra civil entre Pedro I y Enrique II (1366/13691379), las órdenes militares estaban divididas en cuanto al apoyo a uno u otro de los contendientes. Así, las órdenes de Santiago y de Alcántara, que habían seguido a Enrique IV, desde 1474 respaldaron a los reyes Isabel y Fernando (1474-1516). El clavero alcantarino Alonso de Monroy, sobrino del maestre Gutierre de Sotomayor ${ }^{100}$, que al principio fue partidario de los reyes de Castilla, ayudó a Afonso V y a Juana, lo mismo que la orden de Calatrava y el marqués de Villena. La orden del Hospital estuvo dividida en su prudente actitud; el prior Juan de Valenzuela asistió a Afonso $\mathrm{V}$ y pudo haber estado en Toro.

Con estos apoyos, la estrategia de los Reyes Católicos (1474-1504) se basaba en mantener la presión hasta conseguir la victoria definitiva y para ello controlaron y atacaron por tierra en la frontera meridional. Así, habían pedido a uno de los maestres de Alcántara, Francisco Solís, que les haría servicio haciendo alguna entrada en Portugal, por lo que con doscientos caballos y quatrocientos infantes entró por la parte de Alburquerque y tomó la fortaleza de Ouguela ${ }^{101}$. Alonso de

96. Costa A, 2016, pp. 6-9. En el ejército estaban las órdenes portuguesas, sin que haya sido posible cuantificar sus efectivos. En el inicio del siglo XV, João I obligaba a las órdenes a facilitar trescientas cuarenta lanzas para la defensa el reino: Cristo y Santiago debían aportar cien cada una, Avis ochenta y el Hospital sesenta.

97. Pino, 1992, pp. 280-281; Mazo, 1981, p. 429.

98. Bernaldez, 1962, pp. 48-49 y 52; Moreno, 1993, p. 105: Rui de Pina nombra cinco mil seiscientos caballeros y catorce mil peones; Pulgar, 2008, 1, pp. 120-121, 127-131 y 158-160; Lora, 2008, p. 1627.

99. Palencia, 1908, II, p. 222; Cabrera, 1988, p. 85; Pulgar, 2008, 1, pp. 118-119, 121 y 146-147.

100. Rodríguez Casillas, 2013b, pp. 45-46.

101. Rades, 1980, Alcántara, f. 50r; Moreno, 1993, p. 107; Torres, 1999, II, f. 428; Rodríguez Casillas, 2013a, p. 61. 
Monroy se había escapado de su arresto o liberado de él y, apoyado en una hueste formada por fugitivos y homiziados, combatió en el alfoz de Plasencia a las tropas del conde de Plasencia, ya enfrentados por el dominio de la orden de Alcántara ${ }^{102}$. Monroy continuaría con sus combates y tomó incluso la encomienda hospitalaria de Trevejo ${ }^{103}$.

Afonso $\mathrm{V}$, sin duda preocupado por la defensa de la frontera, había designado como fronteros en la Beira y en el Alentejo a los obispos de Coimbra, João Galvão y de Évora, García de Meneses ${ }^{104}$. Hizo bien, pues en junio de 1475, mientras las tropas de Sevilla se adentraban en Portugal y tomaban Noudar, la reina Isabel, siguiendo la táctica de control de la frontera pidió a Alonso de Cárdenas que entrase en Portugal, por tierras extremeñas hacia el Alentejo: faga la dicha guerra al dicho reyno de Portogal, a fuego e a sangre, entrando en el dicho reyno de Portogal e tomando e devastando e destruyendo qualesquier villas e logares ${ }^{105}$. Enfrente estaban las órdenes de Avis y de Santiago.

Lugares situados en la parte occidental del Guadiana, como Noudar, Ouguela o Moura u otras en la Beira, como Segura, pertenecientes a la orden de Avis, cambiaron pues de manos en julio de $1475^{106}$. Los soberanos que habían incorporado a su bando a los Sotomayor de Belálcazar y que habían conseguido, por la mediación del prior del Hospital Álvaro de Stúñiga, la reconciliación entre el conde de Feria y Alonso de Cárdenas, pidieron a varias villas que ayudasen a la orden de Alcántara en caso de necesidad. Los portugueses sitiaron Ouguela por lo que el maestre Francisco Solís acudió en su defensa; allí encontraría la muerte ${ }^{107}$. Alonso de Cárdenas, al ver que Portugal estaba vacío de gente de guerra, invadió y arrasó todo lo que encontró en quince leguas adentro del reino. Junto al conde de Feria, neutralizó los intentos de invasión del príncipe João que se dirigió entonces hacia el reino de Sevilla, en donde se enfrentó a los nobles con dominios en esa frontera. El obispo de Évora se refugió en el castillo de Mérida que estaba ocupado por la condesa de Medellín, hija de Juan Pacheco ${ }^{108}$.

En enero de 1476, los reyes Isabel y Fernando que, al morir el maestre Solís, habían perdido un oponente de los Stúñiga, otorgaron una provisión real en favor de Alonso de Monroy al que recuperaron para su causa y nombraron maestre; este había recobrado Trujillo unos meses antes y había atacado y tomado Alegrete y Arronches. En junio acudió a luchar a la frontera de Portugal y entró en sus tierras ganando una refriega a gente de Olivenza en el mojón de Guadapero, en donde se utilizaron escopetaros a caballo y junto a tropas del conde de Feria y de la orden

102. Lora, 2003, p. 191; 2008, p. 1633; Rodríguez Casillas, 2013b, p. 104.

103. Montaña, 2009b, p. 218.

104. Palencia, 1908, II, p. 247; Pulgar, 2008, 1, p. 148.

105. AGS, Registro General del Sello, I, 520, 20 de junio de 1475, cit. Moreno, 1994, p. 55; Torre, Suárez (eds.), 1958, I, pp. 84-85, doc. 23.

106. Oliveira, Monteiro, 2018, p. 276.

107. Torres, 1999, II, ff. 428-429; Gomes, 2009, pp. 268-269.

108. Bernaldez, 1962, vol. 1, p. 90; Pino, 1992, p. 283; Moreno, 1993, p. 110. 
de Santiago, devastó la frontera del Alentejo ${ }^{109}$. La reina Isabel había mandado al prior de la orden del Hospital, Álvaro de Stúñiga, que no sólo combatiera al rey de Portugal sino también al arzobispo de Toledo, al marqués de Villena y al maestre de Calatrava ${ }^{110}$. Las órdenes militares seguían pues en pie de guerra en estos litigios entre las monarquías de Portugal y de Castilla, en una guerra de fronteras.

Los días 2 y 3 de marzo de 1476 tenía lugar la batalla de Toro de la que cada bando reivindicó ser el vencedor. Pero sí fue considerada una victoria política de los Reyes Católicos y el punto de partida de las desilusiones de Afonso V sobre su proyecto ibérico. En ella participaron las órdenes portuguesas de Avis y Santiago pues estaban bajo el gobierno del príncipe João; en cambio, las crónicas no citan a las órdenes castellanas. Las de Alcántara y Santiago defendían la frontera extremeña a donde se dirigió el príncipe luso después de Toro para preservarla de los ataques de Alonso de Monroy en el Alentejo ${ }^{111}$.

\section{LA CONTINUACIÓN DE LA BATALLA DE TORO}

Isabel y Fernando emprendían ahora una ardua tarea, la reconciliación interior del reino con los linajes nobles, los concejos y las órdenes militares -Calatrava y Alcántara- que habían apoyado a doña Juana ${ }^{112}$. Se produjeron muchos movimientos de adhesión y obediencia a los monarcas castellanos, como los Stúñiga que negociaron el acercamiento a los reyes, que en abril reconocían a Juan de Stúñiga como maestre de Alcántara ${ }^{113}$. Rodrigo Girón volvió a la obediencia de los reyes, lo que le permitió conservar el maestrazgo de Calatrava que había asumido de nuevo Alonso de Aragón al entrar en el reino castellano en apoyo de los reyes, en 1476 y estuvo en Toro. Se le restablecieron a Rodrigo sus bienes; el maestre sería ya fiel a Isabel y Fernando ${ }^{114}$. También lo harían otros Grandes de Castilla.

El 11 de noviembre de 1476, moría el comendador mayor de Castilla de la orden de Santiago, Rodrigo Manrique, conde de Paredes. La reina Isabel

se trasladó a Uclés y comunicó la decisión de que el rey Fernando se adjudicaba la administración de la orden durante seis años, al cabo de los cuales haría entrega del cargo a los freires; esta decisión representaba relegar a Alfonso de Cárdenas, uno de sus hombres de confianza. Al año siguiente, el monarca devolvía la administración a la orden y los freires elegían a Alonso de Cárdenas como maestre ${ }^{115}$.

109. Palencia, 1908, II, p. 282; Rades, 1980, Alcántara, ff. 50v-51r; Moreno, 1993, p. 109; Torres, 1999, II, ff. 432-436; Rodríguez Casillas, 2013a, pp. 168-169.

110. Torre, Suárez, 1958, I, pp. 100-102, doc. 34; Moreno, 1993, p. 110.

111. García de Resende, 2007, cap. XV, cit. Rodríguez Casillas, 2017, p. 297.

112. Álvarez P, p. 11.

113. Lora, 1991, p. 300; 2003, p. 196.

114. Pulgar, 2008, 1, pp. 274-277.

115. Álvarez P, p. 13. 
En 1477, los reyes tuvieron noticias de que las gentes de Portugal entraban por las partes de Badajoz y de Ciudad Rodrigo a facer guerra en Castilla e asimismo, que los de aquellas fortalezas de Castronuño e las otras de aquella comarca que estaban por el rey de Portugal, facian guerra a todas aquellas partes. Así enviaron poderes al comendador mayor de Santiago en León y al conde de Feria para que defendiesen la tierra e hiciesen guerra al reino de Portugal. Por ello entraron varias veces en Portugal y trajeron robados muchos ganados e bestias e prisioneros e rescate de hombres, como la correría que ejecutó Alonso de Cárdenas en la zona de Vero. Este llegaría a reunir cerca de mil caballos y, en caso de necesidad a más de diez mil peones ${ }^{116}$.

En febrero, el príncipe João cercaría Alegrete que se rendiría dos meses después, a pesar de las demandas apremiantes de ayuda de Alonso de Monroy a los reyes, que nunca llegaría ${ }^{117}$. En mayo-junio, el maestre de Santiago recuperaría Alegrete y se dispuso a atacar Évora, con unas huestes compuestas por dos mil de a caballo y numerosos de a pie. El príncipe João se les enfrentó y derrotó en la batalla de Mourão perdiendo un centenar de hombres. A mediados de ese año, D. João recuperaba Noudar y tomó los castillos de Zagala y Piedrabuena en territorios de la orden de Alcántara ${ }^{118}$. En todas esas entradas, con resultados tan cambiantes, hubo enfrentamientos, con muertos y presos por ambas partes $e$ de contino avía entréllos cruda guerra.

Los monarcas castellanos pensaron que, al acercarse a esos territorios desde Trujillo, podrían influir en la guerra y pacificar esa provincia, tan expuesta desde hacía años a robos, e tiranías de algunos caballeros e por los alcaydes de las fortalezas della ${ }^{119}$. Si se ha de creer a Alonso de Palencia,

Isabel tuvo la tentación de ir mucho más allá del papel que tradicionalmente se atribuía a las reinas en un contexto bélico. Así explica que, cuando en 1477 se dirigía hacia Trujillo, la reina fue tentada por algunos para que, en actuación seguramente aventurada y poco adecuada para las facultades femeninas, se pusiera al frente de las tropas y marchara contra Portugal, con el objetivo de dirigirse al monasterio de Batalla y recuperar el pendón real castellano que allí se conservaba. La reina pedía al concejo de Trujillo que proporcionase a Alonso de Monroy una fuerza de veinticinco lanzas para la guarnición de Peñafiel ${ }^{120}$.

Aunque la tendencia era a negociar, al final de la guerra hubo incidentes puntuales en Galicia y Extremadura. En Galicia, en los inicios de 1478 tropas portuguesas al mando de Pedro Álvarez de Sotomayor, tomaron ciertos lugares y ganaron Tuy. En Extremadura, el duque de Arévalo, Álvaro de Stúñiga pedía ayuda a los monarcas para poder conservar su dominio sobre la villa y castillo de Segura,

116. Rades, 1980, Santiago, f. 49v; Rodríguez Casillas, 2013a, p. 97.

117. Rodríguez Casillas, 2013b, pp. 62.

118. Gois, 1905, cap. XCVI, pp. 247-250, cit. Moreno, 1993, p. 113; Costa A, 2011, p. 127.

119. Pulgar, 2008, 1, pp. 290-292; Rodríguez Casillas, 2008, p. 272.

120. Palencia, 1908, III, p. 35; Torre, Suárez, 1958, I, p. 136, doc. 66. 
en la frontera y cerca de Alcántara ${ }^{121}$. A pesar de los acuerdos de paz de San Juan de Luz en octubre de 1478 y el firmado por D. João en Évora en septiembre ${ }^{122}$, Afonso V quiso continuar la guerra con Castilla pero sus súbditos pidieron al príncipe João que pusiera fin a las hostilidades mediante unas treguas ${ }^{123}$. El alcalde de Moura se rebeló contra Afonso y se sometió a los reyes de Castilla al abrir la fortaleza a las tropas de Alonso de Cárdenas. En mayo don Fernando pidió en Andalucía el reclutamiento de un ejército para invadir Portugal, pero el príncipe João tomó Moura ${ }^{124}$.

Se complicaba la situación debido a la decepción de Alfonso de Monroy ya que suponía que sus prestaciones con los monarcas iban a ser recompensadas con el maestrazgo de Alcántara pero Sixto IV había otorgado el maestrazgo a Juan de Stúñiga ${ }^{125}$. Monroy pasó a favorecer al bando portugués, junto a Beatriz Pacheco, condesa de Medellín. El comendador santiaguista Rodrigo de Cárdenas se enfrentó a Alonso de Monroy con ciento cincuenta lanzas, entre Mérida y Valverde, al que derrotó $^{126}$. A pesar de la opinión contraria de D. João, el obispo de Évora, García de Meneses, y su hermano entraron en febrero de 1479 en territorio castellano con una fuerza estimada en mil de a caballo, entre los que había doscientos cincuenta castellanos, además de otros ciento ochenta de la orden de Alcántara partidarios de Alonso de Monroy, aunque las cifras difieren de un cronista a otro ${ }^{127}$. Fueron derrotados cerca de Mérida en la batalla del río Albuera por el maestre Alonso de Cárdenas con quinientos caballeros santiaguistas, cuatrocientos de las Hermandades sevillanas y cien/quinientos peones ${ }^{128}$.

Ya que Mérida, Medellín y Montánchez seguían en poder del rey portugués, el maestre las cercó por orden de la reina Isabel pues sabía que si quería ganar la guerra debía controlar esos castillos que aún estaban en rebeldía ${ }^{129}$. Allí fue donde el rey Fernando acordó con el maestre santiaguista que mantuviese una fuerza de entre diez mil y quince mil peones ${ }^{130}$. Mérida se rindió cinco meses después, así como Medellín, al establecerse las paces de Alcáçovas-Trujillo, en 1479. A pesar de ellas, en ese mismo año se documentan las algaradas de Pedro de Alburquerque, alcalde de Sabugal, en el término de Ciudad Rodrigo ${ }^{131}$. En 1480, los Reyes Católicos ratifican a Juan de Stúñiga como maestre de Alcántara, ordenan le sean entregadas todas las fortalezas y mandan que se le reconozca

121. A.G.S., Registro General del Sello, f. 211, cit. Montaña, 2008a, p. 18.

122. Oliveira, Monteiro, 2018, p. 275.

123. Rodríguez Casillas, 2017, p. 298.

124. Cosme, 1992, p. 394.

125. Pulgar, 2008, 1, p. 362; Pino, 1992, p. 94-100.

126. Bernaldez, 1962, p. 79.

127. Palacios B, 2003a, II, p. 340, doc. 1244, 1477, diciembre 20, Roma; p. 353, doc. 1254, 1478, agosto 11, Bracciano; p. 372.

128. Bernaldez, 1962, p. 80; Rodríguez Casillas, 2013a, p. 165-168; Oliveira, Monteiro, 2018, p. 277.

129. Rodríguez Casillas, 2013a, p. 152.

130. Rades, 1980, Santiago, ff. 70r-71r; Pino, 1992, p. 360, doc. 20; Pulgar, 2008, 1, p. 382; Orozco, Parra, 2017, pp. 401-402 y 409.

131. Martins, 1999, p. 107. 
en todo el maestrazgo, a la par que deniegan las pretensiones del embajador de Portugal, Fernando de Silva, para que reconociesen como maestre de Alcántara a Alonso de Monroy; la petición se repetirá en 1482. Monroy continuaría con sus reivindicaciones maestrales; los reyes le prohibían utilizar el título de maestre en $1495^{132}$.

Al tiempo de estos episodios se cerraron los momentos de las luchas armadas y comenzaron los de la búsqueda de la paz. Así, la reina Isabel de Castilla y su tía Beatriz de Braganza, cuñada de Afonso Vy madre del duque de Viseu y maestre de Cristo, se encontrarían en Alcántara en marzo de 1479 y concertaron las condiciones de paz. Serán las paces de Alcáçovas-Trujillo en septiembre, ratificadas por las de Toledo en marzo de 1480 y por Sixto IV por la bula Aeterni Patris ${ }^{133}$. Con esos acuerdos, no sólo se cerraron los episodios bélicos, sino que se solucionaron todos los temas pendientes. Se replantearon los problemas dinásticos, políticos, económicos y comerciales entre los dos reinos y se acordaron matrimonios que añadirían argumentos para la paz.

El tratado de Tordesillas, en 1494, puso fin a los litigios entre Castilla y Portugal.

\section{CONCLUSIONES}

Las relaciones entre Castilla y Portugal en el primer tercio del siglo XV fueron el resultado de los conflictos, treguas y paces del final del siglo anterior, con las dos nuevas dinastías. Si desde el tratado de Medina del Campo-Almeirim de 1431-1432 parecía establecida una paz definitiva entre Castilla y Portugal, los desacuerdos entre los dos estados conducirán a enfrentamientos bélicos, mezclados con negociaciones de nuevas paces y treguas hasta alcanzar acuerdos permanentes. La guerra civil castellana y las aspiraciones de Afonso $\mathrm{V}$ al trono de Castilla resucitaron los conflictos que ya había conocido la frontera durante el reinado de Juan II. Para ello, las monarquías plantearán y efectuarán mejoras en sus ejércitos con nuevas técnicas y tácticas, fruto de sus contactos con los protagonistas de la Guerra de los Cien Años, a pesar de la composición heteróclita de los ejércitos en lucha, en los que, al contrario, las órdenes militares destacaron por su organización y eficacia. Así, los monarcas supieron apreciar esa contribución premiando a las órdenes y a sus maestres ${ }^{134}$.

De la importancia de las órdenes militares para los reyes, basta indicar que João I decía - en palavras de Fernão Lopes-, o meestrado de Christus e de Santiago e o dAvis e o priol do Esprital que sam asy como quatro collunas que sostem

132. Palacios B, 2003a, II, p. 384, doc. 1275, 1480, enero 13, Toledo; p. 442, doc. 1333, 1480, julio 25, Toledo; p. 396, doc. 1287, 1480, marzo; p. 435, doc. 1327, 1482, junio antes del 28; AGS, Registro General del Sello, C. Cédulas. Libro 1, p. 351. Cédula, 2, cit. Rodríguez Casillas, 2013b, pp. 66-67.

133. Mendonça, 2004, p. 24; Oliveira, Monteiro, 2018, p. 277.

134. Monteiro, 1998a, pp. 274-275. 
a honrra de meu reyno ${ }^{135}$. En este siglo las órdenes portuguesas estaban divididas en cuanto al apoyo al regente D. Pedro o a la reina Leonor. Ocurrirá lo mismo al final de la regencia con la victoria de Afonso V en Alfarrobeira. Las órdenes nunca dejaron de interesar a los monarcas, lo que hizo que los maestrazgos de las órdenes estuvieran siempre en manos seguras y fieles, por lo que no es de extrañar que no fueran un peligro para los reyes; su sucesión estuvo siempre bajo control. Así la titularidad de las órdenes nacionales de Portugal fue otorgada, desde 1418, a infantes de la casa real portuguesa para su administración y gobierno y fueron absorbidas directamente por el monarca, en 1551-1522 ${ }^{136}$. Los maestres de las órdenes militares castellanas fueron cercanos a la Corona, segundones de nobles titulados o miembros de la familia real. La integración de las órdenes en la corona de Castilla se inició con los Reyes Católicos, entre 1489 y 1494, aunque su incorporación no llegó hasta 1523.

La participación de las órdenes militares en los conflictos armados, patrocinados y animados por los monarcas castellanos y portugueses, se sucedieron a lo largo de los siglos XIII al XV, como una evolución reflejo de la de la propia monarquía en los últimos siglos de la Edad Media ${ }^{137}$. Ello les llevaría a enfrentarse entre sí y en las luchas internas de Castilla o de Portugal, con una única y extraordinaria excepción: la batalla del Salado, en 1340. En sus intervenciones, las órdenes militares castellanas y portuguesas formarán parte de las huestes de los monarcas en las que también estarán las de los nobles y de los concejos de las ciudades, villas y lugares de los reinos. En cambio, serán las órdenes las que operen en misiones de frontera o de limitadas incursiones en territorio enemigo; estaban mejor preparadas para ellas que para batallas campales.

En la primera mitad del siglo XV, la nobleza y las órdenes militares, en concreto las de Santiago y Alcántara, participaron de lleno en los conflictos de frontera, pues los combates y la política se desarrollaron en sus territorios con éxitos cambiantes y que llevaron la destrucción a sus dominios. En la segunda mitad del siglo, en la guerra civil castellana y en la guerra de sucesión, se produjeron divisiones importantes en las dos órdenes citadas; los apoyos o las decisiones de los maestres y dignatarios de las mismas a uno u otro bando condicionaron el desarrollo de las contiendas. Fueron batallas campales en la cuenca del Duero y se desplazaron hacia el sur, en una guerra de fronteras, en territorios pertenecientes a las órdenes militares. Como indica el profesor García Fitz, esos combates podrían ser descritos como una guerra de sucesión de devastaciones, frecuentes asedios y, rara vez, alguna batalla ${ }^{138}$.

La frontera no fue sólo el escenario de esos enfrentamientos, sino que puso de manifiesto el interés de unos y otros por su control y por llevarlo al otro lado de la raya, como un signo indudable de una estrategia encaminada al desgaste del contrario. Así, la frontera era para João I,

135. Lopes, 1990, II, p. 402, cit. Martins M, 2018, p. 336.

136. Costa P, 2004, p. 2; Fonseca, 2016, p. 694, nota 37; Lencart, 2016, pp. 80-81, nota 11.

137. Cabrera, 2000, p. 284.

138. García Fitz, 1998a, p. 45. 
no sólo el centro de la atención de la administración militar portuguesa, con los fronteros mayores, o de las mejoras de las fortificaciones de la frontera con Castilla, sino también el corazón de la guerra, de las ofensivas tácticas en las que las campañas militares debidamente planificadas dieran la expresión para que la estrategia se revelase efectivamente vencedora ${ }^{139}$.

La guerra de sucesión castellana fue la tercera tentativa en la Baja Edad Media de reunificación de Castilla y Portugal, después de las reivindicaciones del trono castellano por Fernando I de Portugal y del trono portugués por Juan I de Castilla. Como escribió el cronista portugués Rui de Pina, el futuro Juan II de Portugal se habría lamentado más tarde de la no cristalización de la política castellanizante de su padre, argumentando que de aquella forma la familia real portuguesa hubiera llegado a ser 'd'Espanha pacífycos Reis e Senhores '140. Todas esas pretensiones se manifestaron en las guerras correspondientes, sin alcanzar su objetivo.

En el tratado de paz de 1479-1480 -Alcáçovas-Tujillo y Toledo- se negociaron entre Portugal y Castilla asuntos pendientes y uno de ellos fue la cuestión dinástica castellana tratada en las tercerías de Moura. Fueron intentos de relanzar esas posibilidades de unión pero que no se verían reflejadas en la realidad. Tanto los tratados de Alcáçobas-Toledo como el de Tordesillas (1494) ratificaron los de Medina del Campo-Almeirim de 1431-1432 ${ }^{141}$, al proceder en cada uno a ampliar y a precisar algunos aspectos que surgían en el desarrollo de sus relaciones. Castilla y Portugal habian comprendido el alcance de la política orientada hacia otras tierras y la necesidad de una paz entre ambos ${ }^{142}$.

Por último, señalar que la intervención de las órdenes militares en estos conflictos, en particular en las guerras de fronteras, abre un abanico muy interesante de historia militar, en cuanto a profundizar en el estudio de la participación en ellos de cada encomienda, de los propios comendadores y de otros cargos, así como de la financiación, de las respectivas tropas y reclutamientos y de su relación con la población de sus dominios. Y no solo en la parte extremeña, más estudiada, sino en toda la raya entre los dos reinos.

\section{BIBLIOGRAFÍA CITADA}

Almeida, Fortunato de (1967), História da Igreja em Portugal, Porto, I, p. 350, cit. Moreno, Humberto Baquero (2000), “As Ordens Militares na sociedade portuguesa do século XV. O apogeu e a queda do Mestrado de Santiago", en Izquierdo Benito, Ricardo y Ruiz Gómez, Francisco (coord.), Las órdenes militares en la Península Ibérica, 1, Cuenca, pp. 773-796.

139. Monteiro, 2000, p. 149.

140. Pina, 1901, p. 829, cit. Fonseca, 1986, p. 461.

141. Álvarez Palenzuela.

142. Romero, 2002, p. 196; 2003, p. 65. 
Álvarez Palenzuela, Vicente Ángel, La guerra civil castellana y el enfrentamiento con Portugal (1475-1479), Biblioteca virtual Miguel de Cervantes. Disponible en: http/www.cervantesvirtual.com.

Ayala Martínez, Carlos de; Barquero Goñi, Carlos; Matellanes, José Vicente; Novoa Portela, Feliciano; Rodríguez-Picavea Matilla, Enrique (1992), "Las Ordenes Militares en la Edad Media Peninsular. Historiografía (1977-1992), I. Reinos de Castilla y León”, Medievalismo, 2, pp. 119-169.

Ayala Martínez, Carlos de; Andrés Robres, Fernando; Matellanes Merchán, José Vicente; Silva, Isabel Luisa Morgado de Sousa e; Novoa Portela, Feliciano; Pimenta, María Cristina; Rodríguez-Picavea Matilla, Enrique (1993), “Las Órdenes Militares en la Edad Media Peninsular. Historiografía 1976-1992. II. Corona de Aragón, Navarra y Portugal", Medievalismo, 3, pp. 87-144.

Ayala Martínez, Carlos de (2003), Las Órdenes Militares Hispánicas en la Edad Media (siglos XII-XV), Madrid.

Ayala Martínez, Carlos de (2006), "Frontera y órdenes militares en la Edad Media castellano-leonesa (siglos XII-XIII)", Studia Historica. Historia Medieval, 24, p. 87-112. Disponible en: https://revistas.usal.es/index.php/Studia_H_Historia_ Medieval/article/view/4521/4537.

Ayala Martínez, Carlos de (2019a), "Pedro I y las órdenes militares", Memoria y civilización, 22, pp. 63-92. Disponible en: https://revistas.unav.edu/index.php/ myc/article/view/37727/32905.

Ayala Martínez, Carlos de (2019b), "La investigación en órdenes militares en España (1989-2019)", Ordens Militares, Identidade e Mudança, Palmela, VIII Encontro sobre Ordens Militares, en prensa.

Barbosa, Isabel María de Carvalho Lago (1998), “A Ordem de Santiago em Portugal nos finais da Idade Media, Militarium Ordinum Analecta, 2, pp. 93-288. Disponible en: https://www.cepese.pt/portal/pt/publicacoes/obras/militarium-ordinum-analecta-n.o-2.

Barquero Goñi, Carlos (1998), "Disputas por el priorato del Hospital en Castilla, ss. XIV-XV”, Hispania, LVIII/2, 199, pp. 537-557.

Bernaldez, Andres (1962), Memorias del reinado de los Reyes Católicos, Madrid.

Boix Salvador, Juan (2020), "Encuentros y desencuentros de las órdenes militares en las guerras de fronteras entre Castilla y Portugal en el siglo XIV", Medievalismo, 30, pp. 39-74. Disponible en: https://medievalistas.es/revista-medievalismo-no-30-2020/.

Cabrera Muñoz, Emilio (1988), "En torno a una enconada rivalidad por el Maestrazgo de Calatrava durante el siglo XV", Espacio, tiempo y forma. Serie III, Historia medieval, 1, págs. 75-96. Disponible en: http://revistas.uned.es/index. $\mathrm{php} / \mathrm{ETFIII} /$ article/view/3494.

Cabrera Muñoz, Emilio (2000), "El acceso a la dignidad de maestre y las divisiones internas de las Ordenes Militares durante el siglo XV" en Izquierdo Benito, Ricardo; Ruiz Gómez, Francisco (coord.) Las órdenes militares en la Península Ibérica, 1, Cuenca, pp. 281-306. 
Castrillo Llamas, $\mathrm{M}^{\mathrm{a}}$ Carmen (1997), La tenencia de fortalezas en la Corona de Castilla durante la Baja Edad Media, siglos XII-XV, Madrid, Universidad Complutense, (tesis doctoral).

Corral Val, Luis (1998), La orden de Alcántara: organización institucional y vida religiosa en la Edad Media, Madrid, Universidad Complutense, (tesis doctoral).

Cosme, João dos Santos Ramalho (1992), "O reflexo das rivalidades luso-castelhanas no espaço Raiano (1165-1580). O caso dos concelhos de Moura, Mourão, Olivença e Serpa", Revista de Estudios Extremeños, XLVIII, 2, pp. 377-404. Disponible en: https://www.dip-badajoz.es/cultura/ceex/reex_digital/reex XLVIII/1992/T.\%20XLVIII\%20n.\%202\%201992\%20mayo-ag/RV10996.pdf.

Costa, António Carlos Martins (2011), A batalha de Toro e as relações entre Portugal e Castela. Dimensões políticas e militares na segunda metade do século $X V$, Lisboa, Universidad de Lisboa, (Dissertação de Mestrado em História Medieval).

Costa, António Carlos Martins (2016), “As ordens militares em combate nos finais da Idade Média: o caso da guerra de Susessão de Castela (1475-1479)", Medievalista online, 19, pp. 1-32. Disponible en: https://journals.openedition. org/medievalista/1007.

Costa, Paula Pinto (2000), “A Ordem Militar do Hospital em Portugal: Dos Finais da Idade Média à Modernidade", Militarium Ordinum Analecta, 3/4, pp. 5-592. Disponible en: https://www.cepese.pt/portal/pt/publicacoes/obras/militarium-ordinum-analecta-n.o-3-4.

Costa, Paula Pinto (2004), "The Military Orders Established in Portugal in the middle Ages: A Historiographical Overview", e-JPH, 2, 1, pp. 1-16. Disponible en: https://www.brown.edu/Departments/Portuguese_Brazilian_Studies/ ejph/html/issue3/pdf/ppcosta.

Costa, Paula Pinto (2019), Templários em Portugal. Homens de religão e de guerra, Lisboa.

Fonseca, Luís Adão da (1972), "Alguns aspectos das relações diplomáticas entre Portugal e Castela em meados do século XV (1449-1456)", Historia. Revista da Faculdade de Letras, 3, pp. 51-112. Disponible en: https://ojs.letras.up.pt/ index.php/historia/article/view/5867.

Fonseca, Luís Adão da (1982), O Codestável D. Pedro de Portugal, a orden de Avis e a Península Ibérica do seu tempo (1429-1466), Porto.

Fonseca, Luís Adão da (1983), “Algumas considerações a propósito da documentãçao existente em Barcelona respeitante ã Ordem de Avis: sua contribução para um meilhor conhecimento dos grupos de pressão em Portugal em meados do século XV", Jornadas sobre Portugal Medieval, Leiria, pp. 19-56.

Fonseca, Luís Adão da (1986), "Una elegía inédita sobre la familia de Avis", Anuario de Estudios Medievales, 16, pp. 449-463.

Fonseca, Luís Adão da (2000), “A comenda de Noudar da Ordem de Avís: a memória da frontera entre a Idade Média e a Idade Moderna" en Izquierdo Benito, Ricardo; Ruiz Gómez, Francisco (coord.), Las órdenes militares en la Península Ibérica, 1, Cuenca, pp. 655-681. 
Fonseca, Luís Adão da (2004), “As ordens militares e a expansão" en Oliveira e Costa, JP; Rodrigues, VL Gaspar (eds.) A alta nobreza e a fundação do estado da Índia, Lisboa, pp. 321-347.

Fonseca, Luís Adão da (2005), D. João II, Lisboa.

Fonseca, Luís Adão da (coord.) (2013), “Comendas das Ordens Militares: perfil nacional e inserção internacional. Noudar e Vera Cruz de Marmelar", Militarium Ordinum Analecta, 17. Disponible en: https://www.cepese.pt/portal/pt/ publicacoes/obras/militarium-ordinum-analecta-n-o-17.

Fonseca, Luís Adão da (2016), "La Orden de Cristo entre la cruzada y la monarquía: Un marco ideológico con finalidad política” en Torres Jiménez, Raquel; Ruiz Gómez, Francisco, (eds.) Órdenes Militares y construcción de la sociedad occidental, (siglos XII-XV), Madrid, pp. 681-699.

García Fitz, Francisco (1998a), Ejército y actividades guerreras en la Edad Media europea, Madrid.

García Fitz, Francisco (1998b), Castilla León frente al Islam. Estrategias de expansión y tácticas militares, Sevilla.

García Fitz, Francisco (2007), "Las guerras de cada día” en la Castilla del siglo XIV", Edad Media, Revista de Historia, 8, pp. 145-181.

García Fitz, Francisco; Novoa Portela, Feliciano (2018), "El papel militar de las Órdenes en los conflictos civiles castellanos del siglo XV" en Fernandes, Isabel C. (coord.) Entre Deus e o Rei. O mundo das ordens militares, Palmela, Coleção Ordens Militares, 8.1, pp. 371-390.

García de Resende (2007), Vida e feitos D'El Rey Dom João II, Edición crítica de Evelina Verdelho, Coimbra.

Gois, Damião de (1905), Chronica do Prinçipe Dom Joam, Coimbra.

Gomes, Saul António (2009), D. Afonso V: o Africano, Lisboa.

González Sánchez, Santiago (2013), Las relaciones exteriores de Castilla a comienzos del siglo XV: la minoría de Juan II (1407-1420), Madrid.

Izquierdo Benito, Ricardo; Ruiz Gómez, Francisco (coord.) (2000), Las órdenes militares en la Península Ibérica, 1, Cuenca.

Ladero Quesada, Manuel Fernando (1982), "La orden de Alcántara en el siglo $\mathrm{XV}$ : Datos sobre su potencial militar, territorial, económico y demográfico", En la España Medieval, 2, pp. 499-542. Disponible en: https://revistas.ucm.es/ index.php/ELEM/article/view/ELEM8282120499A/25374.

Ladero Quesada, Miguel Ángel (1993), "Formación y funcionamiento de las huestes reales en Castilla en el siglo XV", Actas de las II Jornadas Nacionales de Historia Militar, Málaga, pp. 162-173. Disponible en: http://www.catedrageneralcastanos.org/documentos/pdf/La_Organizacion_Militar_en_los_Siglos_ XV_y_XVI.

Ladero Quesada, Miguel Ángel (2009), “Baja Edad Media” en O’Donnell, Hugo (coord.) Historia militar de España, II, Madrid, pp. 217-378.

Lencart, Joana (2016), "Los libros de Álvares Seco sobre la orden de Cristo (15301580)" en Torres Jiménez, Raquel; Ruiz Gómez, Francisco, (eds.) Órdenes 
Militares y construcción de la sociedad occidental, (siglos XII-XV), Madrid, pp. 73-100.

Lopes, Fernão (1990), Crónica de D. João I, Porto.

Lora Serrano, Gloria (1991), "La organización de la defensa militar de un estado señorial y el potencial bélico de un noble a mediados del siglo XV", $H I D, 18$, p. 300. Disponible en: https://revistascientificas.us.es/index.php/HID/article/ view/5883

Lora Serrano, Gloria (1998), “Señoríos y frontera: La nobleza extremeña ante la guerra luso-castellana de sucesión", Història, Revista da Faculdade de Letras, Porto, 15/1, pp. 383-410. Disponible en: https://ojs.letras.up.pt/index.php/historia/article/view/5562.

Lora Serrano, Gloria (2003), "La lucha por la obtención del Maestrazgo de Alcántara. Violencia y abusos señoriales en la Extremadura del siglo XV", Revista de las Órdenes Militares", 2, pp. 163-196.

Lora Serrano, Gloria (2008), "Matrimonio y Poder en la Extremadura Medieval. Consideraciones sobre la vida de Juan de Estúñiga, Maestre de Alcántara", Revista de Estudios Extremeños, LXIV-3, pp. 1593-1638. Disponible en: https://www.dip-badajoz.es/cultura/ceex/reex_digital/reex_LXIV/2008/T.\%20 LXIV\%20n.\%203\%202008\%20sept.-dic/RV001980.

Maldonado, Alonso de (1978), Vida e historia del Maestre de Alcántara don Alonso de Monroy, Tarragona.

Marques, José (2009), "Relações fronteiriças luso-castelhanas, nos séculos XIVXV", Ibéria: Quatrocentos/ Quinhentos, duas décadas de catédra. Homenajem a L. A. Fonseca, Porto, pp. 91-141. Disponible en: https://www.cepese.pt/ portal/pt/publicacoes/obras/iberia-quatrocentos-quinhentos.

Martín Martín, José Luis (1994), "La frontera hispano-portuguesa en la guerra, la paz y el comercio" en Carabias Torres, Ana María (ed.) Relaciones entre Portugal y Castilla en la época de los descubrimientos y la expansión colonial, Salamanca, pp. 29-52.

Martínez Teixidó, Antonio (2014), Operaciones militares de la orden de Santiago en las Edades Media y Moderna, Madrid, UAM, (tesis doctoral).

Martins, Miguel Gomes, (2018), "As hostes das ordens militares em Portugal entre os finais da reconquista e inícios do século XV - Composição e dimensão" en Fernandes, Isabel C. (coord.), Entre Deus e o Rei. O mundo das ordens militares, Palmela, Coleção Ordens Militares 8.1, pp. 321-336.

Martins, Miguel Gomes; Monteiro, João Gouveia (2018), "Portugal. II. The Late Middle Ages 1249-1367: A time of reforms and royal consolidation", en García Fitz, Francisco; Monteiro, João Gouveia (eds.) War in the Iberian Peninsula, 700-1600, Abingdon, pp. 212-241.

Martins, Rui Cunha (1999), "La frontera medieval Hispano-Portuguesa (el punto de vista de la guerra)" en Vaca Lorenzo, Ángel (ed.) La guerra en la Historia, Salamanca, pp. 95-114.

Mattoso, José (1992), “A monarquia feudal”, História de Portugal, II: A monarquia feudal (1096-1480), Lisboa. 
Mattoso, Jose (dir.) (2012), The Historiography of Medieval Portugal, c. 19502010, Lisboa.

Mazo Romero, Fernando (1980), El condado de Feria (1394-1505), contribución al estudio del proceso señorializador en Extremadura durante la baja Edad Media, Badajoz.

Mazo Romero, Fernando (1981), "La intervención del segundo Conde de Feria en la guerra de Sucesión Castellano-Portuguesa", Revista de Estudios Extremeños, XXXVII-2, pp. 429-454. Disponible en: https://www.dipbadajoz.es/cultura/ceex/reex_digital/reex_XXXVII/1981/T.\%20XXXVII\%20n.\%202\%20 1981\%20mayo-ag/RV10720.

Mendonça, Manuela (1995), "As ordens de Cristo e Santiago nos primórdios da Expanção Portuguesa (séculos XIV-XV)", Amar, sentir e viver a História, Lisboa, pp. 859-884.

Mendonça, Manuela (2004), "De Alcáçovas a Tordesillas: A terra de Vera Cruz", História. Revista, 9.1, pp. 21-34. Disponible en: https://dialnet.unirioja.es/ ejemplar/378778.

Montaña Conchiña, Juan Luis de la (2008a), "E Levaram Captivos, e derribaram o logar todo" La guerra en la frontera castellano-portuguesa (siglos XIV-XV)", Norba, 21, pp. 11-28.Disponible en: https://www.historiauex.es/revista/norba_artculos_37/n_21_ao_2008_412.

Montaña Conchina, Juan Luis de la (2008b), "La red comendataria alcantarina en el siglo XV", Revista de Estudios Extremeños, LXIV-2, pp. 717-759. Disponible en: https://www.dip-badajoz.es/cultura/ceex/reex_digital/reex_LXIV/2008/T.\%20LXIV\%20n.\%202\%202008\%20mayo-ag/RV001532.

Montaña Conchiña, Juan Luis de la (2009a), "La Historia medieval en Extremadura: 25 años de investigación”, Norba, 22, pp. 57-83. Disponible en: https:// www.historiauex.es/revista/norba_artculos_37/n_22_ao_2009_411.

Montaña Conchiña, Juan Luis de la (2009b), "Conflictos antiseñoriales en un espacio de frontera: la encomienda hospitalaria de Trevejo en el siglo XV", Castilla y el mundo feudal, III-VI, pp. 215-227.

Montaña Conchiña, Juan Luis de la (2014), "Vida rural, ganadería y comercio en la frontera castellano-portuguesa. El sector extremeño (siglos XIII-XV)", Revista de Estudios Extremeños, LXX-2, pp. 893-920. Disponible en: https://www. dip-badajoz.es/cultura/ceex/reex_digital/reex_LXX/2014/T.\%20LXX\%20 n.\%202\%202014\%20mayo-ag/72408.

Monteiro, João Gouveia (1998a), "Arcaísmo o modernidade no Exército Português nos finais da Idade Média? O contributo das Ordens Militares" en Fernandes, Isabel Cristina (coord.) Ordens Militares. Guerra, religão, poder e cultura, Palmela, III Encontro, II, pp. 259-275.

Monteiro, João Gouveia (1998b), A guerra em Portugal nos finais da Idade Média, Lisboa.

Monteiro, João Gouveia (2000), “A Fronteira Luso-Castelhana nas preocupações militares da Monarquia Portuguesa (1350-1450)", Revista Militar, 52, 2/3, pp. 133-151. 
Monteiro, João Gouveia (coord.) (2001), Aljubarrota Revisitada, Coimbra.

Monteiro, João Gouveia; Martins, Miguel Gomes (2010), As Cicatrizes da Guerra no Espaço Fronteiriço portugués (1250-1350), Coimbra.

Moreno, Humberto Baquero (1979), “A contenda entre D. Afonso V e os Reis Católicos: incursões castelhanas no solo português de 1475 a 1478", Anais da Academia Portuguesa da Historia, II Série, 25, pp. 295-324.

Moreno, Humberto Baquero (1980), A batalla de Alfarrobeira. Antecedentes e significado histórico, Coimbra.

Moreno, Humberto Baquero (1993), "Os Confrontos Fronteiriços entre D. Afonso V e os Reís Católicos" Revista da Faculdade de Letras. História, II Série, 10, pp. 103-116. Disponible en: https://ler.letras.up.pt/uploads/ficheiros/2233.

Moreno, Humberto Baquero (1994), “As Relaçoes entre Portugal e Castela em torno de 1492" en Carabias Torres, Ana Mª (ed.) Las relaciones entre Portugal y Castilla en la época de los descubrimientos y la expansión colonial, Salamanca, pp. 53-62.

Moreno, Humberto Baquero (1997), “A sociedade de fronteira hispano portuguesa no século XV", Castilla y Portugal: en los albores de la Edad Moderna, Valladolid, pp. 9-18.

Moreno, Humberto Baquero (1999), O mestrado de Santiago no séc. XV. In Ordens Militares. Guerra, religião, poder e cultura. Lisboa: Colibri and C.M. Palmela, vol. 1: 17-38.

Moreno, Humberto Baquero (2000), “As Ordens Militares na sociedade portuguesa do século XV. O apogeu e a queda do Mestrado de Santiago" en Izquierdo Benito, Ricardo; Ruiz Gómez, Francisco (coord.) Las órdenes militares en la Península Ibérica, 1, Cuenca, pp. 773-796.

Novoa Portela, Feliciano; Ayala Martínez, Carlos de (ed.) (2005), Las Órdenes Militares en la Europa medieval, Barcelona.

Novoa Portela, Feliciano; Fernandes, Isabel Cristina (2006), “Consolidar la paz, ganar nuevos mundos: el tratado de Medina del Campo-Almeirim (1431)" en Albuquerque, Martim de, Novoa Portela, Feliciano (coords.) Encuentros y Desencuentros Ibéricos, Barcelona, pp. 73-87.

Oliveira Marques, António de (1987), Portugal na Crise dos Séculos XIV e XV, Lisboa.

Oliveira, António Resende de; Monteiro, João Gouveia (2018), Historia medieval de Portugal (1096-1495), Granada.

Oliveira, Luís Filipe (2009), A Coroa, os Mestres e os Comendadores. As Ordens Militares de Avís e de Santiago (1330-1449), Algarve.

Oliveira, Luís Filipe (2019), “A investigação em Ordens Militares em Portugal”, Ordens Militares, Identidade e Mudança, Palmela, VIII Encontro sobre Ordens Militares, en prensa.

Olivera Serrano, César (2018), "Pax in Bello: la difícil paz entre Castilla y Portugal (1369-1431)", Vínculos de Historia, 7, pp. 46-60. Disponible en: https:// redib.org/Record/oai_articulo1553903-pax-bello-la-dif\%C3\%ADcil-paz-entre-castilla-y-portugal-1369-1431. 
Orozco, Pedro de; Parra, Juan de la (1978), [Primera] Historia de la Orden de Santiago. Manuscrito de la RAH, Badajoz, cit. López Fernández, Manuel (2017), "El maestrazgo de Alfonso Méndez de Guzmán en la Orden de Santiago (1338-1342)”, HID, 44, pp. 151-178. Disponible en: https://revistascientificas.us.es/index.php/HID/article/view/4443.

Palacios Martín, Bonifacio (2003a), Colección diplomática medieval de la orden de Alcántara (1157?-1494), Madrid.

Palacios Martín, Bonifacio (2003b), "La cuna y la sepultura: algunos aspectos biográficos de Juan de Sotomayor, maestre de la orden de Alcántara", Revista de las Órdenes Militares, 2, pp. 129-159.

Palacios Ontalva, Santiago (2018a), “Una aproximación al concepto de 'lanza' en relación a las órdenes militares" en Fernandes, Isabel Cristina (coord.) Entre Deus e o Rei. O mundo das Ordens Militares, Palmela, I, p. 297-320.

Palacios Ontalva, Santiago (2018b), "Los ejércitos de las órdenes militares hispanas. Otra aproximación acerca del valor numérico de sus contingentes" en Ayala Martínez, Carlos de; Palacios Ontalva, Santiago (eds.) Hombres de religión y guerra. Cruzada y guerra santa en la Edad Media peninsular (siglos $X-X V)$, Madrid, pp. 209-239.

Palencia, Alonso de (1908), en A. Paz y Meliá (ed.) Crónica de Enrique IV, Madrid.

Pimenta, Maria Cristina Gomes (1997), “A Ordem Militar de Avís (durante o mestrado de D. Fernão Rodrigues Sequeira)", Militarium Ordinum Analecta, 1, pp. 127-242. Disponible en: https://www.cepese.pt/portal/pt/publicacoes/obras/ militarium-ordinum-analecta-n.o-1.

Pimenta, Maria Cristina Gomes (2000), "Algunas reflexões sobre o fundo documental da Ordem de Avís na Idade Media”, en Izquierdo Benito, Ricardo; Ruiz Gómez, Francisco (coord.) Las órdenes militares en la Península Ibérica, 1, Cuenca, pp. 87-109.

Pimenta, Maria Cristina Gomes (2001), “As ordens de Avís e de Santiago na Baixa Idade Média: o governo de D. Jorge", Militarium Ordinum Analecta, 5, pp. 7-600. Disponible en: https://www.cepese.pt/portal/pt/publicacoes/obras/militarium-ordinum-analecta-n.o-5.

Pimenta, Maria Cristina (2003), “As Ordens de Avis e de Santiago no século XV: o antes e o depois de Alfarrobeira. Breve abordagem”, en Luís Adão da Fonseca (coord.) Os Reinos Ibéricos na Idade Média, III, Porto, pp. 987-994.

Pimenta, Maria Cristina; Silva, Isabel Morgado (1995), "Las Ordenes Militares en Portugal”, Las Ordenes Militares y Caballerescas en la Edad Moderna, Historia 16, XX, 225, Madrid, pp. 70-75.

Pina, Rui de (1901), Chronica de El-Rei D. Affonso V, Lisboa.

Pino García, José Luis del (1987), "Extremadura en vísperas de la invasión portuguesa", Actas das II Jornadas Luso-Espanholas de História Medieval, Porto, pp. 385-400. Disponible en: http://opac.regestaimperii.de/lang_en/ anzeige.php? buchbeitrag $=$ Extremadura $+\mathrm{en}+\mathrm{v} \% \mathrm{C} 3 \% \mathrm{AD}$ speras $+\mathrm{de}+\mathrm{la}+\mathrm{inva}-$ si $\% \mathrm{C} 3 \% \mathrm{~B} 3 \mathrm{n}+$ portuguesa\&pk $=1733884$. 
Pino García, José Luis del (1992), Extremadura en las luchas políticas del siglo $X V$, Badajoz.

Pulgar, Hernando del (2008), en Juan de Mata Carriazo (ed.), Crónica de los Reyes Católicos, Granada.

Rades y Andrada, Francisco de (1980), Crónica de las tres Órdenes de Santiago, Calatrava y Alcántara, Barcelona.

Repertório Bibliográfico da Historiografia Portuguesa. Disponible en: http://porbase.bn.pt.

Rodríguez Casillas, Carlos J. (2008), “La historia militar: más allá de la descripción del acontecimiento. El ejemplo de la frontera luso-extremeña en el contexto de la Guerra de Sucesión de 1475", Revista de Historiografía, 28, pp. 259-276. Disponible en: https://e-revistas.uc3m.es/index.php/REVHISTO/ article/view/4216/2801.

Rodríguez Casillas, Carlos J. (2013a), «A fuego e sangre». La guerra entre Isabel la Católica y doña Juana en Extremadura (1475-1479), Mérida.

Rodríguez Casillas, Carlos J. (2013b), D. Alonso de Monroy (s. XV) Maestre de Alcántara y señor de la guerra, Badajoz.

Rodríguez Casillas, Carlos J. (2017), "Más allá del Duero: La guerra de Sucesión en Extremadura (1475-1479)", Medievalismo, 27, pp. 285-301. Disponible en: https://revistas.um.es/medievalismo/article/view/310671.

Rodríguez Casillas, Carlos J. (2019), "Nuevas aportaciones sobre la campaña de Juan II contra los Infantes de Aragón en Alburquerque (1429-32)", e-Strategica, 3, pp. 247-267. Disponible en: https://www.journal-estrategica.com/pdf/ numero-3/campana-de-juan\%20ii-contra-los-infantes-de-aragon-en-alburquerque.

Rodríguez-Picavea Matilla, Enrique (2005), "Linaje y poder en la Castilla Trastámara. El ejemplo de la orden de Calatrava", Anuario de Estudios Medievales, 35/1 pp. 91-130. Disponible en: http://estudiosmedievales.revistas.csic.es/index.php/estudiosmedievales/article/view/136/138.

Rodríguez-Picavea Matilla, Enrique (2007), "Caballería y nobleza en la Orden de Calatrava: Castilla, 1350-1450”, Anuario de Estudios Medievales, 37/2, pp. 711-740. Disponible en: http://estudiosmedievales.revistas.csic.es/index.php/ estudiosmedievales/article/view/51/52.

Rodríguez-Picavea Matilla, Enrique (2008), Los Monjes Guerreros en los reinos hispánicos, Madrid.

Romero Portilla, Paz (2002), "La manipulación de la causa alfonsina en Castilla. 1464-1468”, Espacio, Tiempo y Forma, Serie III, Ha Medieval, XV, pp. 195206. Disponible en: http://revistas.uned.es/index.php/ETFIII/article/view/3679.

Romero Portilla, Paz (2003), "Protagonismo del partido portugués en la política castellana del siglo XV", História, Revista da Faculdade de Letras, III Série, 4, pp. 187-212. Disponible en: https://ojs.letras.up.pt/index.php/historia/article/view/5102. 
Romero Portilla, Paz (2007), "Relaciones entre Portugal y Castilla en el siglo XV. La situación de Galicia”, Simposio de Estudios Humanísticos, La Coruña, pp. 55-67.

Rosell, Cayetano (ed.) (1953), Crónica de Juan II, Crónicas de los Reyes de Castilla, Madrid.

Silva, Isabel L. Morgado de Sousa e (1994), “O Infante D. Henrique, «Mestre» da Ordem Militar de Jesus Cristo”, Mare Liberum, 7, Lisboa, pp. 9-16. Disponible en: http://www.cidehusdigital.uevora.pt/ophir-restaurada/mare-liberum/volume-7/o-infante-d-henrique-mestre-da-ordem-militar-de-jesus-cristo?pag=16.

Silva, Isabel L. Morgado de Sousa e (1997), "A Ordem de Cristo durante o mestrado de D. Lopo días de Sousa (1373?-1417), Militarium Ordinum Analecta, 1, pp. 5-126. Disponible en: https://www.cepese.pt/portal/pt/publicacoes/obras/ militarium-ordinum-analecta-n.o-1.

Silva, Isabel L. Morgado de Sousa e (2002), "A Ordem de Cristo (1417-1521)", Militarium Ordinum Analecta, 6, pp. 5-503. Disponible en: https://www.cepese.pt/portal/pt/publicacoes/obras/militarium-ordinum-analecta-n.o-6.

Solano Ruiz, Emma (1978), La Orden de Calatrava en el siglo XV. Sevilla.

Suárez Bilbao, Fernando (1994), Enrique III, Palencia.

Suárez Fernández, Luis (1960a), Castilla, el Cisma y la crisis conciliar (13781440), Madrid.

Suárez Fernández, Luis (1960b), Relaciones entre Portugal y Castilla en la época de Enrique III. 1393-1406, Madrid.

Torre, Antonio de la; Suárez Fernández, Luis, (eds.) (1958), Documentos referentes a las relaciones con Portugal durante el reinado de los Reyes Católicos, Valladolid.

Torres y Tapia, Alonso de (1999), Crónica de la orden de Alcántara, Mérida.

Vasconcelos, António Pestana de (2006), "Os Vasconcelos e as ordens militares. Algunas considerãçoes em torno de una linhagem" en Fernandes, Isabel C. (coord.) As ordens militares e as ordens de cavalaria entre o Occidente e o Oriente, Palmela, V Encontro, pp. 247-258.

Vasconcelos, António Pestana de (2012), "Nobreza e Ordens Militares. Relações Sociais e de Poder, séculos XIV a XVI", Militarium Ordinum Analecta, 12, pp. 10-1020. Disponible en: https://www.cepese.pt/portal/pt/publicacoes/obras/ militarium-ordinum-analecta-n.o-12.

Ventura, Margarida Garcez (1998), "Os coutos de homiziados nas fronteiras com o direito de asilo", História, Revista da Facultade de Letras, II série, 15-1, Porto, pp. 601-625. Disponible en: https://ojs.letras.up.pt/index.php/historia/ article/view/5572.

Vicens Vives, Jaime (2003), Juan II de Aragón (1398-1479), Monarquía y revolución en la España del siglo $X V$, $2^{\mathrm{a}}$ edición, Pamplona.

Zurita, Jerónimo (1562), Anales de la Corona de Aragón, en Canellas López, Ángel (ed.) (2007), Zaragoza. 
